\title{
Functional materials, device architecture, and flexibility of perovskite solar cell
}

\author{
Istiak Hussain ${ }^{1} \cdot$ Hoang Phong $\operatorname{Tran}^{1} \cdot$ Jared Jaksik $^{1} \cdot$ Justin Moore ${ }^{1} \cdot$ Nazmul Islam $^{1} \cdot$ M. Jasim Uddin ${ }^{1}$
}

Received: 14 June 2018 / Accepted: 18 September 2018 / Published online: 12 November 2018

(C) The Author(s) 2018

\begin{abstract}
Perovskite solar cells (PSCs) are an emerging photovoltaic technology that promises to offer facile and efficient solar power generation to meet future energy needs. PSCs have received considerable attention in recent years, have attained power conversion efficiencies (PCEs) over 22\%, and are a promising candidate to potentially replace the current photovoltaic technology. The emergence of PSCs has revolutionized photovoltaic research and development because of their high efficiencies, inherent flexibility, the diversity of materials/synthetic methods that can be employed to manufacture them, and the various possible device architectures. Further optimization of material compositions and device architectures will help further improve efficiency and device stability. Moreover, the search for new functional materials will allow for mitigation of the existing limitations of PSCs. This review covers the recently developed advanced techniques and research trends related to this emerging photovoltaic technology, with a focus on the diversity of functional materials used for the various layers of PSC devices, novel PSC architectures, methods that increase overall cell efficiency, and substrates that allow for enhanced device flexibility.
\end{abstract}

Keywords Perovskite $\cdot$ Electron-transporting material $\cdot$ Hole-transporting material $\cdot$ Carbon nanotube $\cdot$ Device architecture

\section{Introduction}

Energy shortages have become a global issue in the twentyfirst century. Currently, the majority of the world's energy is generated from fossil fuels such as coal, petroleum, and natural gas; according to the US Energy Information Administration (EIA), in $2016 \sim 65 \%$ of electricity was generated from fossil fuels, and $\sim 20 \%$ was from nuclear energy, while only $\sim 15 \%$ was from renewable energy sources [1]. The urge to develop renewable energy technologies (like hydroelectric, geothermal, wind, and solar) to replace fossil fuelbased energy generation has motivated substantial scientific research. Among the different renewable sources, solar energy is one of the most promising technologies to meet the growing global energy demands and to resolve or mitigate the everincreasing energy crisis due to the depletion of fossil fuels [2]. Although only $1 \%$ of energy production was reported to be

M. Jasim Uddin

mohammed.uddin@utrgv.edu

1 Photonics and Energy Research Laboratory, Department of Chemistry, College of Science, University of Texas Rio Grande Valley, 1201 W University Dr., Edinburg, TX 78539, USA solar-derived in 2013, solar power is projected to become the most significant source of energy by 2050 [3]. Solar energy has several key advantages over other renewable technologies, namely the global distribution of sunlight (in contrast to wind, geothermal, and hydroelectric resources that are localized to certain areas), the lack of hazardous waste generation (in contrast to nuclear energy), and the decentralized nature of solar energy generation [4].

Photovoltaic solar cells work by converting the energy of incident photon's directly to electricity. Over the years, the development of different photovoltaic technologies can be roughly classified into three discrete generations [5]. Firstgeneration $(1 \mathrm{G})$ solar cells are based on silicon wafers which, while they can produce high power conversion efficiencies (PCEs), also have high production costs. With the goal of reducing costs, second-generation (2G) solar cells were developed, which were commonly based on amorphous silicon, copper indium gallium selenide (CIGS), and cadmium telluride (CdTe). However, the performance of $2 \mathrm{G}$ solar cells was generally poor compared to their $1 \mathrm{G}$ counterparts, which has prompted the development of third-generation $(3 \mathrm{G})$ emerging solar cell technologies [6].

Now, research is mainly focused on third-generation solar cells which include copper/zinc/tin sulfide solar cells, dye- 


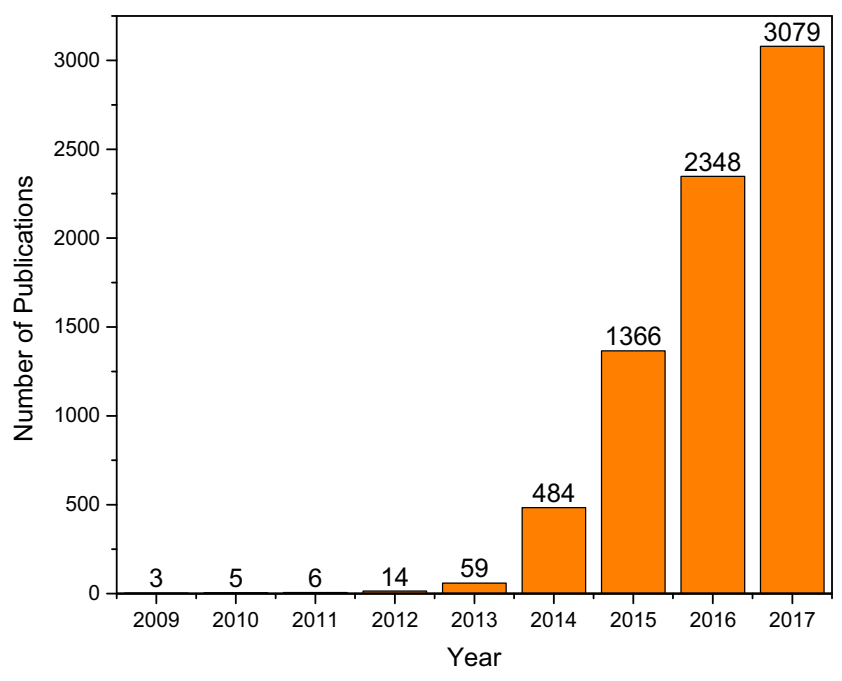

Fig. 1 Research trends in perovskite solar cell based on the number of published articles (data source ISI Web of Knowledge)

sensitized solar cells, organic solar cells, polymer solar cells, quantum dot solar cells, and perovskite solar cells. Between these different $3 \mathrm{G}$ solar cell technologies, PSCs are currently the most rapidly developing technology in terms of the volume of research that has been done on them [7]. In 2009, Kojima et al. for the first time evaluated $\mathrm{CH}_{3} \mathrm{NH}_{3} \mathrm{PbI}_{3}$ (methylammonium lead iodide or $\mathrm{MAPbI}_{3}$ ) and $\mathrm{CH}_{3} \mathrm{NH}_{3} \mathrm{PbBr}_{3}$ (methylammonium lead bromide or $\mathrm{MAPbBr}$ ) as sensitizers in a liquid electrolyte-based dye-sensitized solar cell (DSSC) architecture cell and reported PCEs of 3.81 and $3.13 \%$, respectively [8]. However, because of stability issues and the instant dissolution of perovskite in a liquid electrolyte, this innovation received little attention from photovoltaic researchers. To address this shortcoming, Kim et al. developed a solid-state, highly efficient (PCE 9.7\%), and stable PSC in 2012 by replacing liquid electrolyte with the solid hole conductor [9].

After this discovery, perovskite solar cells have been intensely studied in the last 5 years because of the unique properties of perovskites such as their tunable band gaps [10-12], high absorption coefficients [13, 14], long charge carrier (electron-hole) diffusion lengths [15], and low-temperature solution processability [16]. The significant research efforts into the design of novel device architectures [17-19], careful control of the morphology of each functional layer [20, 21], and optimization of interfacial characteristics [22-24] have enhanced the efficiency of PSCs. These advances have contributed to further research interests in perovskite research community, resulting in a tremendous rise in the number of publications in the last few years, especially in the last 3 years (Fig. 1). In accordance with these trends, the maximum obtained PCE of PSCs has risen from 3.8 to $22.7 \%$ over the previous 8 years (Fig. 2). Herein, we report on the recent advances that have been made in the perovskite solar cell field, which have contributed to improved device efficiency, better materials, novel device architectures, and improved cell flexibility. We first introduce the different device architectures and their current standing in the overall field of photovoltaic research; then, the diverse and advanced functional materials that have been deployed as the various layers of PSCs will be discussed. In the last section, we outline a brief perspective on flexible fiber-type perovskite solar cells.
Fig. 2 The progress in PCE of PSCs: $3.8 \%$ [8], $6.5 \%$ [25], 9.7\% [9], $10.9 \%$ [26], $12.3 \%$ [27], $15.0 \%[28], 15.4 \%$ [20], $16.7 \%$ [29], $18.4 \%$ [30], 19.3\% [22], $20.2 \%$ [13], $20.7 \%$ [31], and $21.6 \%$ [32]. Values in red represent certified efficiencies [33]

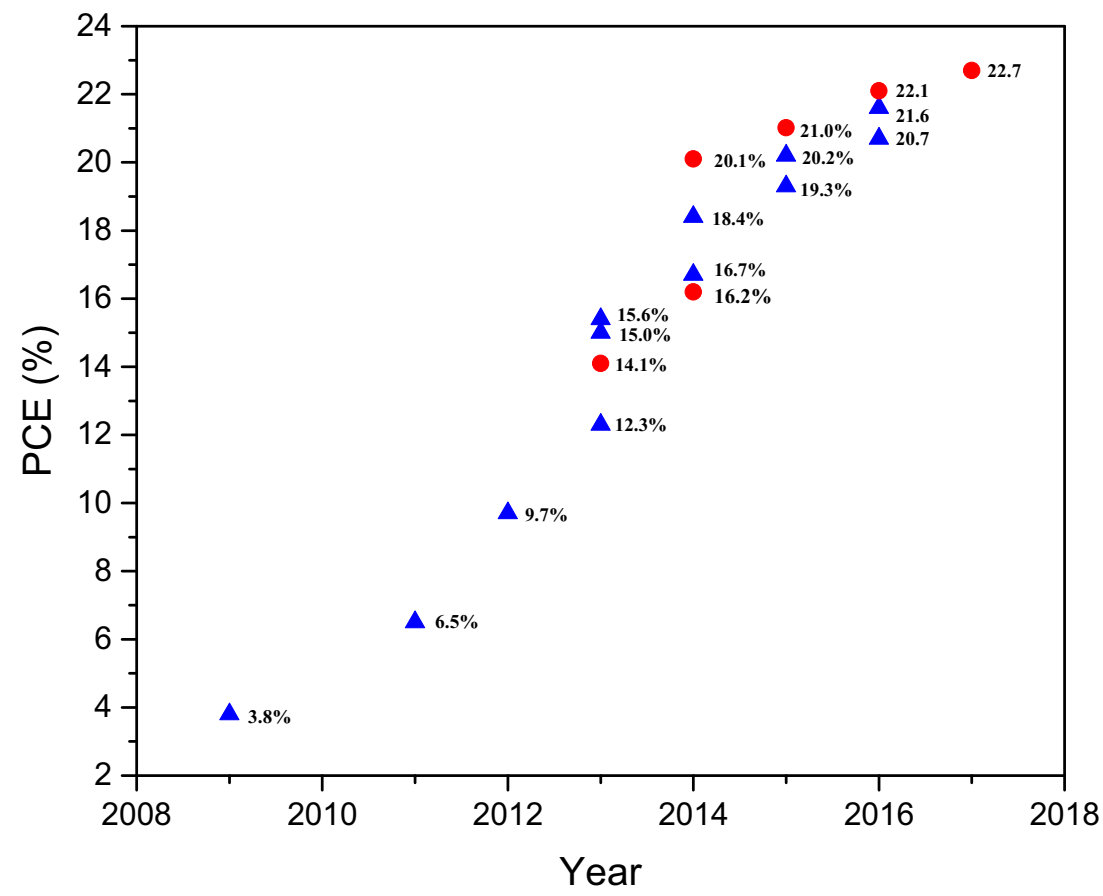


Fig. 3 (a) $\mathrm{ABX}_{3}$ perovskite structure showing $\mathrm{BX}_{6}$ octahedral and larger A cation occupied in cubooctahedral site. (b) The unit cell of cubic $\mathrm{MAPbI}_{3}$ perovskite [35]
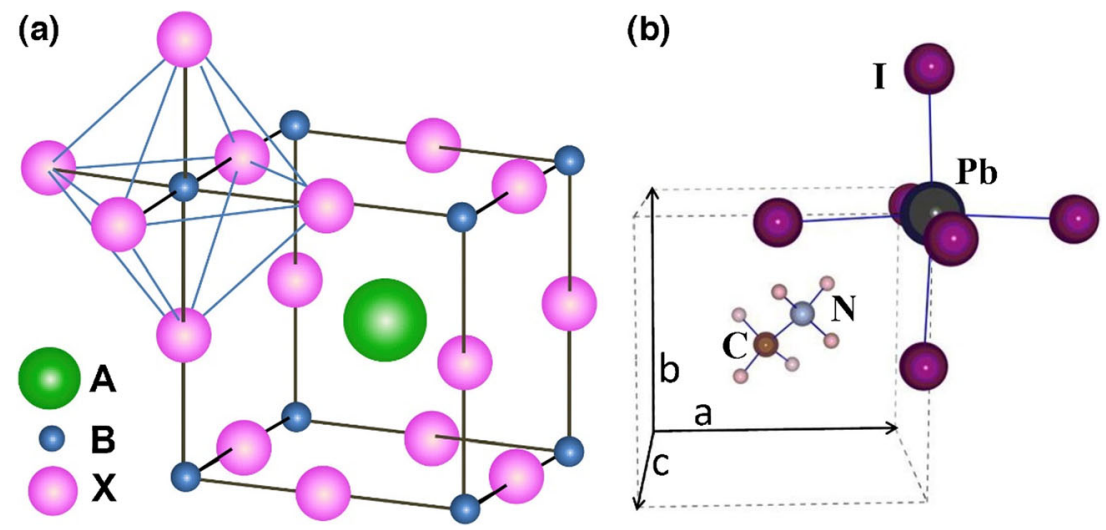

\section{Perovskite crystal structure}

Perovskite is one of the most promising light-harvesting solar cell materials for next-generation photovoltaic cells. It was discovered in 1839 in the Ural Mountains in Russia and named after Russian mineralogist L.A. Perovski [34]. Perovskite is a mineral with the chemical formula $\mathrm{CaTiO}_{3}$ (calcium titanium oxide). Compounds that have a similar structure to $\mathrm{CaTiO}_{3}\left(\mathrm{ABX}_{3}\right)$ are called perovskites. Generally, in the $\mathrm{ABX}_{3}$ structure (Fig. 3a), A is a large monovalent cation which occupies the cubooctahedral sites in a cubic space, $\mathrm{B}$ is a small divalent metal cation occupying the octahedral sites, and $\mathrm{X}$ is an anion (typically a halogen; however, $\mathrm{X}$ can also be oxygen, carbon, or nitrogen). For example, when the $\mathrm{O}^{2-}$ anion is used, $\mathrm{A}$ and $\mathrm{B}$ are usually divalent and tetravalent, respectively [35]. However, when a halogen is present as the anion in a perovskite structure, it results in monovalent and divalent cations in A and B sites, respectively [35].

Two crucial parameters to quantify the structure and stability of perovskites are the tolerance factor $(t)$ and the octahedral factor $(\mu)[35,36]$. The tolerance factor is the ratio of the bond lengths of $\mathrm{A}-\mathrm{X}$ and $\mathrm{B}-\mathrm{X}$ in an idealized solid-sphere model. Mathematically, it can be expressed as:

$t=\frac{\left(R_{\mathrm{A}}+R_{\mathrm{X}}\right)}{\sqrt{\mathbf{2}\left(R_{\mathrm{B}}+R_{\mathrm{X}}\right)}}$

where $R_{\mathrm{A}}, R_{\mathrm{B}}$, and $R_{\mathrm{X}}$ represent the ionic radii of the $\mathrm{A}, \mathrm{B}$, and $\mathrm{X}$, respectively [37]. The octahedral factor $\mu$ is the ratio of the ionic radius of divalent cation $\left(R_{\mathrm{B}}\right)$ and radius of the anion $\left(R_{\mathrm{X}}\right)$. For halide perovskites, these parameters are typically in the following ranges: $0.81<t<1.11$ and $0.44<\mu<0.90$ [38]. Although an ideal 3D cubic perovskite structure has a value of $t=1$, the perovskite material still maintains a stable $3 \mathrm{D}$ cubic structure for $0.89 \leq t \leq 1$. Lower values of $t$ lead to less symmetric tetragonal or orthorhombic structures, whereas high values of $t(t>1)$ could destabilize the 3D B-X network [38]. Calculated values of the tolerance $(t)$ and octahedral factors $(\mu)$ for different perovskites are presented in Fig. 4.
Fig. 4 Calculated values of tolerance factor $(t)$ and octahedral factor $(\mu)$ for halide-based perovskites [37]

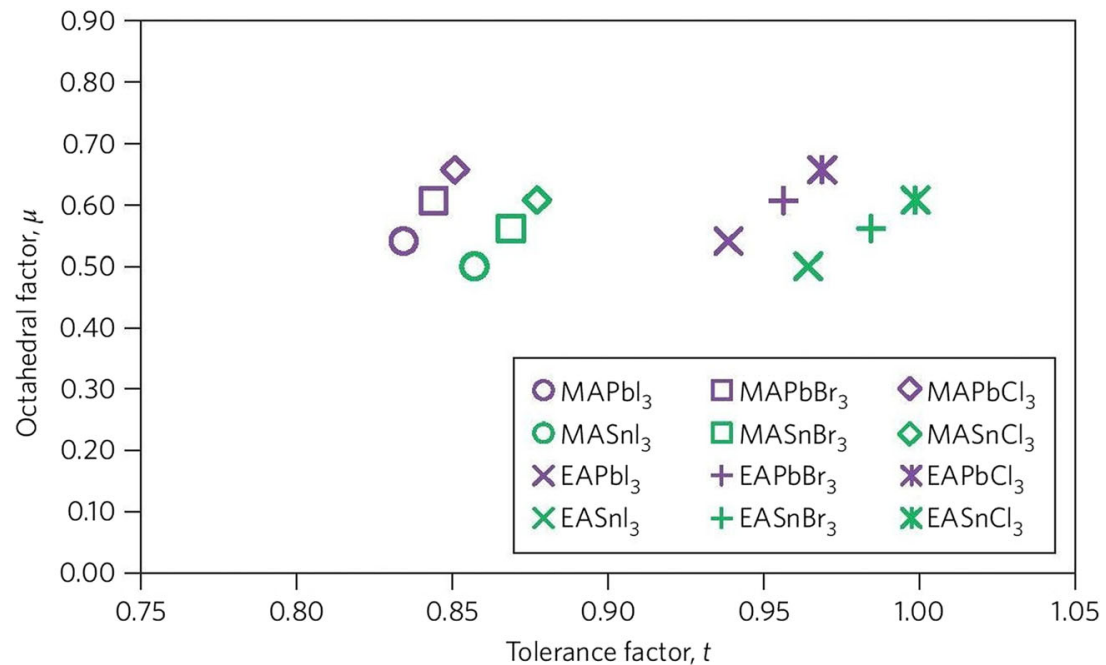




\section{Operation principle of perovskite solar cell}

The operational mechanisms of DSSCs and organic photovoltaics aid in understanding the functioning of PSCs. A schematic representation of the operation principle of PSCs is illustrated in Fig. 5. Perovskite solar cells utilize perovskite structured light absorbers for photovoltaic activity like dyesensitized solar cells utilize the dye/semiconductor interface for light harvesting. The photovoltaic system has three main functioning steps: (1) absorption of photons followed by free charge generation, (2) charge transport, and (3) charge extraction. When sunlight falls on a PSC, the perovskite absorbs light, excitons are generated, and charge carriers (electrons and holes) are produced upon exciton dissociation. Exciton dissociation occurs at the interface between the perovskite layer and the charge-transporting layer. When the electron is separated from the hole and injected into the electrontransporting layer (ETL), it migrates to the anode which is in most cases fluorine-doped tin oxide (FTO) glass. Simultaneously, the hole is injected into the holetransporting layer (HTL) and subsequently migrates to the cathode (usually metal) [40]. The electrons and holes are collected by working and counter electrodes respectively and transported to the external circuit to produce current [41].

\section{Device architecture}

The device configuration is one of the most crucial factors for evaluating the overall performance of perovskite solar cells. PSCs can be classified as regular (n-i-p) and inverted ( $p-i-n)$ structures depending on which transport (electron/hole) material is present on the exterior portion of the cell/encountered by incident light first. These two structures can be further divided into two categories: mesoscopic and planar structures. The mesoscopic structure incorporates a mesoporous layer whereas the planar structure consists of all planar layers.

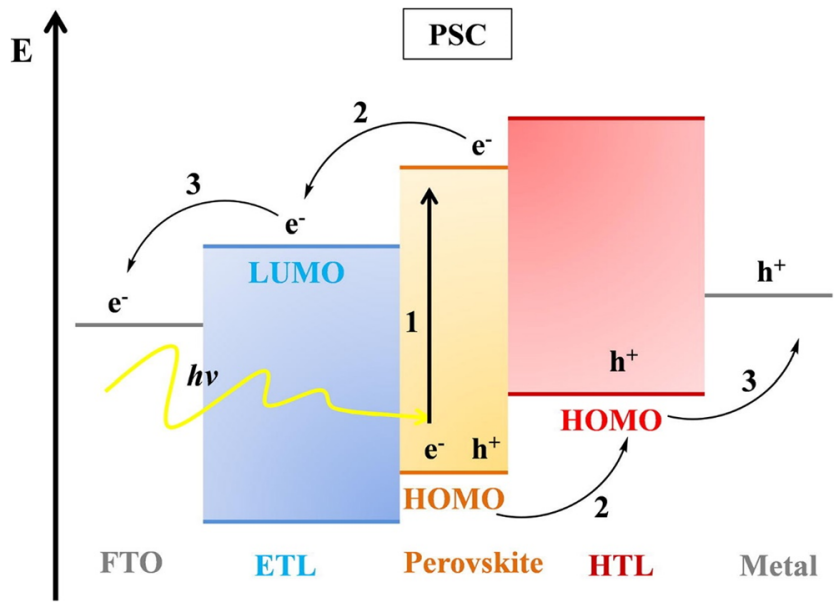

Fig. 5 Band diagram and operation principle of perovskite solar cell [39]
Perovskite solar cells without electron and hole-transporting layers have also been tested. In summary, six types of perovskite solar cell architectures have been studied by various researchers thus far: the mesoscopic n-i-p configuration, the planar n-i-p configuration, the planar $\mathrm{p}-\mathrm{i}-\mathrm{n}$ configuration, the mesoscopic p-i-n configuration, the ETL-free configuration, and the HTL-free configuration.

\subsection{Regular n-i-p structure}

The conventional n-i-p mesoscopic structure was the first arrangement of perovskite photovoltaics to be tested, in which the light-harvesting dye was replaced with lead halide perovskite semiconductors in a traditional DSSC-type architecture [8]. The interest in perovskite solar cells increased more when so-called mesoscopic device structures (Fig. 6a) were formed by substituting the liquid electrolyte with a solid-state holeconducting material [9]. The assembly begins with a transparent glass cathode followed by the electron transportation material (ETM). The structure is then layered with a mesoporous metal oxide containing the perovskite, followed by the hole transport material (HTM), and capped with a metallic anode (Fig. 6a). This initial advancement in PSCs created an important field of interest for photovoltaic researchers and consequently led to the development of other PSC device configurations (Fig. 6b-d). The planar architecture is an evolution of the mesoscopic structure, where the perovskite lightharvesting layer is sandwiched between the ETM and HTM. The absence of a mesoporous metal oxide layer leads to an overall simpler structure. It is possible to achieve a high efficiency without the mesoporous layer by carefully controlling the interfaces between the different layers that make up the PSC (the perovskite light absorber layer, the electrontransporting layer, the hole-transporting layer, the electrodes as well as the perovskite layer itself) [22]. With the same materials and approach, a planar n-i-p PSC shows increased $\mathrm{V}_{\mathrm{OC}}$ (open-circuit voltage) and $\mathrm{J}_{\mathrm{SC}}$ (short-circuit current density) relative to a mesoscopic PSC device; however, the planar configuration also had more severe $\mathrm{J}-\mathrm{V}$ hysteresis which calls into question the accuracy of the reported efficiencies [42]. The grain and thickness of this buffer layer influence the J-V hysteresis behavior [43, 44]. Kim et al. also observed that $\mathrm{J}-\mathrm{V}$ hysteresis problem is significantly dependent on the p-type hole-transporting materials and found that the hysteresis behavior can become negligible with a reduced capacitance, which can be done by replacing Spiro-OMeTAD with poly(3,4-ethylene dioxythiophene)-poly(styrene sulfonate) (PEDOT:PSS) or any other inorganic hole-transporting materials [45]. However, the J-V hysteresis behavior is also dependent on voltage scan direction, scan rate, and range [46]. To counter this problem, a thin mesoporous buffer layer was incorporated within the planar n-i-p PSC structure [13]. To date, the best mesoscopic n-i-p device has exhibited a PCE $21.6 \%$ 
(a) n-i-p mesoscopic

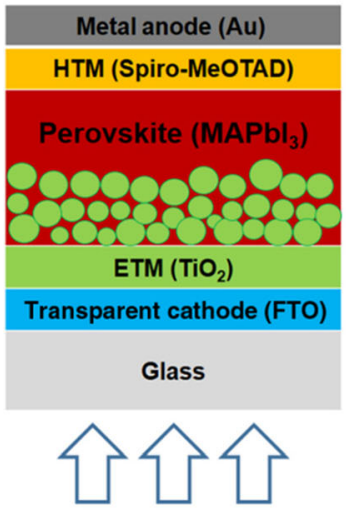

(b) n-i-p planar

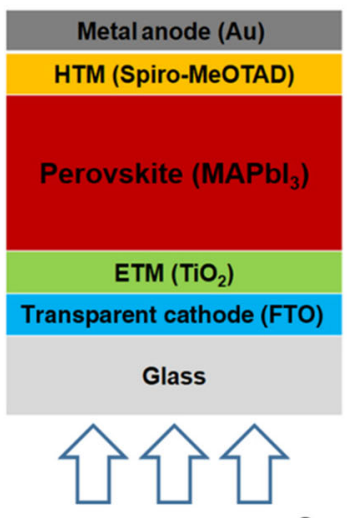

(c) p-i-n planar

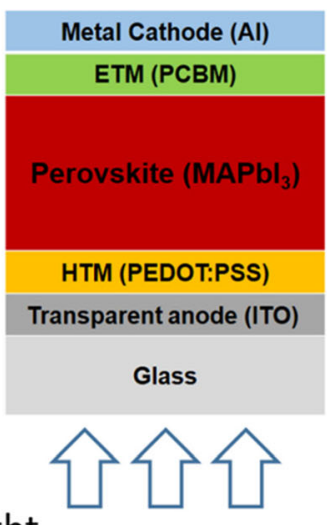

(d) p-i-n mesoscopic

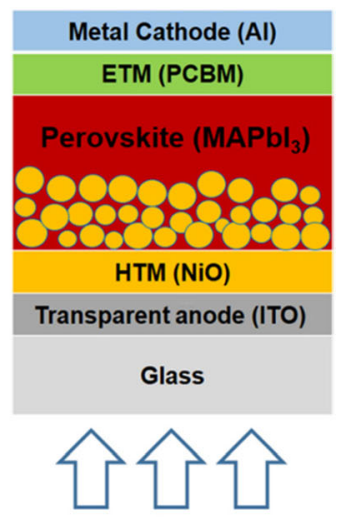

Fig. 6 Schematic showing the layered structure four typical of perovskite solar cells (a) n-i-p mesoscopic, (b) n-i-p planar, (c) p-i-n planar, and (d) p-i-n mesoscopic [42]

[32], whereas the highest reported efficiency of a planar n-i-p cell 20.7\% [31]. Although mesoporous PSC shows better efficiency than planar structure, it is required to have a thinner mesoporous layer (less than $300 \mathrm{~nm}$ ) [25]. In addition, the planar device could be fabricated with a low-temperature process unlike the mesoporous structure [47]. However, better control of the perovskite-absorbing layer is required [47].

\subsection{Inverted p-i-n structure}

The $p-i-n$ PSC structured is derived from the organic solar cell [48]. In the case of the p-i-n planar perovskite architecture, the HTM layer is deposited first followed by the ETM layer. It was discovered that perovskites are capable of transporting the holes themselves [49], which led to Jeng et al. developing the first planar hetero-junction PSC with an inverted structural design [50]. With this advancement, the inverted p-i-n configuration has expanded the options to explore more for selective layer from organic to inorganic materials and the use of oxide HTM allow for constructing mesoscopic p-i-n device architecture [39, 41]. Planar p-i-n PSC offers low-temperature processing, negligible hysteresis behavior with high efficiency of
$18 \%$ [51]. The device configuration of the inverted p-i-n planar and mesoscopic PSC is shown in Fig. 6c, d.

\subsection{Electron-transporting layer-free structure}

A compact n-type metal oxide on the transparent conductive oxide (TCO) is always required for conventional planar perovskite solar cells, as it helps to achieve high open-circuit voltage $\left(\mathrm{V}_{\mathrm{OC}}\right)$ and overall power conversion efficiency. However, $\mathrm{Hu}$ et al. developed a surface modification technique utilizing a cesium salt solution to modify the indiumtin-oxide (ITO) surface/optimize energy level alignment at this interface, which led to a PCE of $15.1 \%$ [52]. Later, Liu et al. developed a compact layer-free PSC which exhibited $13.5 \%$ efficiency by directly depositing the perovskite layer on the ITO surface via a sequential layer deposition method, demonstrating that including an ETL is not a necessity to obtain outstanding device efficiencies [53]. Ke et al. also suggested that a $\mathrm{TiO}_{2}$ electron-transporting material may not be an ideal interfacial material after developing an efficient ETLfree PSC with a PCE of $14.14 \%$ and a $\mathrm{V}_{\mathrm{OC}}$ of $1.06 \mathrm{~V}$ grown directly on an FTO substrate via a one-step solution process
Fig. 7 (a) Schematic illustration of the electron transport layer-free planar mixed halide perovskite solar cell configuration and (b) energy level diagram of the planar PSC showing collection and separation of photo-generated electrons and holes without an ETL [54] a

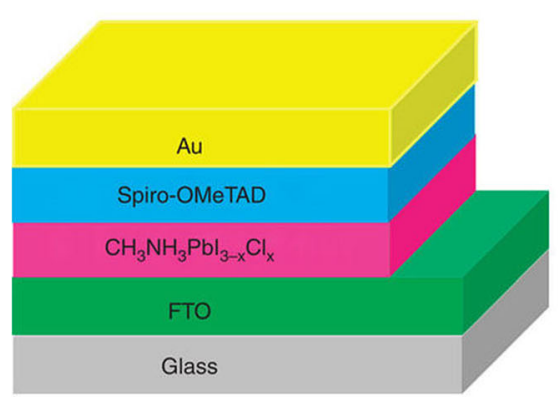

b

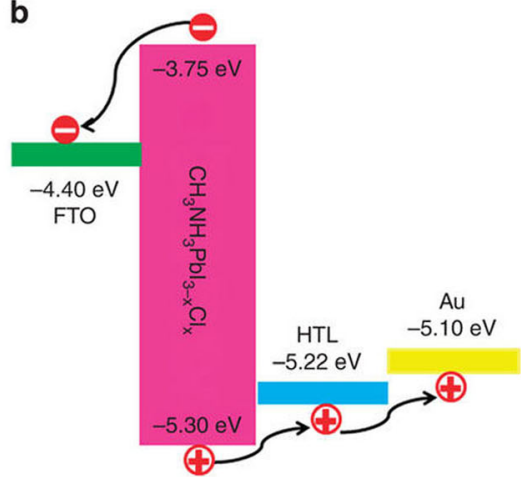


without any hole-blocking layers [54]. The compact ETM layer-free planar perovskite solar cell architecture is shown in Fig. 7. Other studies have also proved that the compact layer-free architecture can exhibit excellent performance when generated with different film-forming methodologies [55-57].

\subsection{Hole-transporting layer-free structure}

Although various novel hole transport materials (HTMs) have been evaluated with good results (including small molecules, polymers, and inorganic compounds), HTM-free PSC architectures are a simpler cell configuration that is garnering increased attention in this field. This increasing emphasis is because most of the reported highly efficient PSCs contain expensive HTMs like fullerenes, which significantly increase the fabrication cost of the cells. As already mentioned, organo-lead halide perovskite materials show outstanding semiconducting properties like long charge transport lifetimes and an ambipolar nature which allows for the exclusion of the hole-transporting layer $[13,14]$. In 2012, Etgar et al. reported the successful fabrication of HTL-free mesoscopic perovskite solar cells for the first time, indicating that $\mathrm{MAPbI}_{3}$ itself performed the function of both a light harvester and hole conductor [49]. Aharon et al. found that the performance of HTL-free PSCs was highly dependent on the depletion layer width because this layer helps in charge separation and prevents the back-reaction of the electrons from the $\mathrm{TiO}_{2}$ with the $\mathrm{MAPbI}_{3}$ film [58]. A remarkable 12.8\% certified efficiency with high stability was obtained in a fully printable hole transport layer-free mesoscopic PSC by using a double layer of mesoporous $\mathrm{TiO}_{2}$ and $\mathrm{ZrO}_{2}$ covered with porous carbon [59]. Enhancing the quality of the perovskite film and further optimization of the ETL/perovskite interface is important for further enhancement of the efficiency of HTM-free PSCs. The most straightforward hole-transporting layer-free PSC structure is shown in Fig. 8.

The different device configuration informs the selection of charge-transport (ETM and HTM) and charge-collection materials (cathode and anode). Recent advances concerning

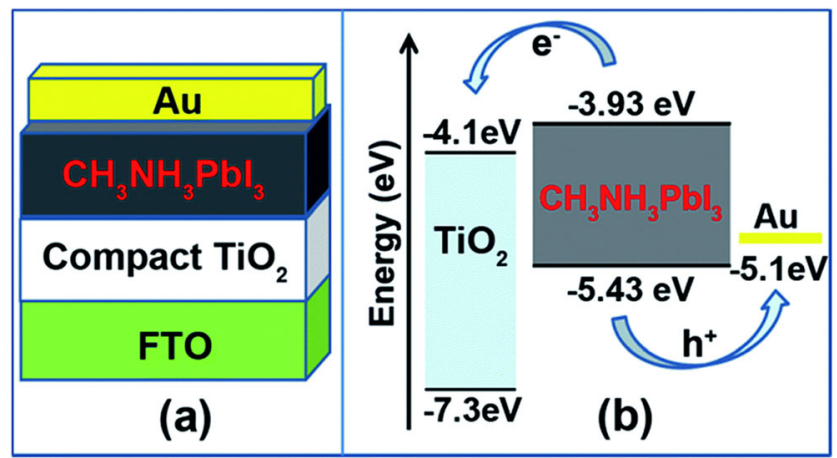

Fig. 8 Schematic illustration of the (a) structure and (b) energy level alignment of the planar hole-transporting layer-free perovskite $\left(\mathrm{CH}_{3} \mathrm{NH}_{3} \mathrm{PbI}_{3}\right)$ solar cells [60] advanced materials for the electron and hole-transporting layers, as well as new materials being developed for use in the perovskite layer, are discussed in the forthcoming sections.

\section{Materials for perovskite solar cell}

The ongoing advancement of perovskite solar cells is remarkable considering both the advancement of new materials for use in the cells and the recent advances towards gaining a more in-depth understanding of perovskite devices' working principles. Both the architecture of the overall perovskite solar cell and the choice of materials used have a significant effect on the resultant device's electronic and optical properties. Moreover, the properties of perovskites can be optimized by changing their elemental composition. The materials used in perovskite solar cells can be categorized into five groups: the transparent conductive oxide (TCO) layer, the electrontransporting layer (ETL), the light-harvesting perovskite material, the hole-transporting layer (HTL), and the metal contact material. In the following subsections, the significant materials that have driven recent research into perovskite-type solar cells are discussed.

\subsection{Perovskite materials}

As previously discussed, perovskites used for light harvesting typically contain a monovalent cation, a divalent cation, and a halide ion. Currently, $\mathrm{MAPbI}_{3}$ is the most common perovskite material for light harvesting. However, other perovskite materials such as mixed cation, mixed halide, and mixed halidemixed cation perovskites are attracting increasing attention since they have some advantages over the traditional $\mathrm{MAPbI}_{3}$ perovskite. Moreover, researchers are trying to find alternative materials to $\mathrm{Pb}$ to avoid the inherent toxicity of lead. In the following three subsections, recent studies and research into a diverse range of materials are discussed.

\subsubsection{Monovalent cation exchange/mixing}

The modification of monovalent cations can improve the performance of PSCs. Although methylammonium lead iodide $\left(\mathrm{MAPbI}_{3}\right)$ is the most commonly used light absorber in perovskite solar cells now, there is an ongoing search for other functional materials to replace methylammonium (MA) in $\mathrm{MAPbI}_{3}$ due to its suboptimal band gap and issues with long-term stability [61]. The optimal band gap for a single junction solar cell is between 1.1 and $1.4 \mathrm{eV}$ while the reported band gaps of $\mathrm{MAPbI}_{3}$ are between 1.50 and $1.61 \mathrm{eV}$ [62].

The solar light-harvesting efficiency of PSCs can be further enhanced by using lower band gap perovskites than $\mathrm{MAPbI}_{3}$. For a lead halide-based perovskite, modification of the monovalent cation may lead to a change in the $\mathrm{Pb}-\mathrm{I}$ bond length and 
angle and, consequently, a change in the overall band structure [13]. Exchanging the MA ion with slightly larger organic formamidinium (FA) ion results in a cubic structure with a somewhat larger lattice and thus a slight decrease in the band gap from $1.59 \mathrm{eV}$ for $\mathrm{MAPbI}_{3}$ to $1.45-1.52 \mathrm{eV}$ for $\mathrm{FAPbI}_{3}$ which is closer to the optimal band gap of a single junction solar cell and, therefore, allows for the harvesting of more light [63]. Also, Hanusch et al. showed that $\mathrm{FAPbI}_{3}$ is thermally more stable than both $\mathrm{MAPbI}_{3}$ and $\mathrm{MAPbBr}_{3}$ which strongly supports the findings that larger cation at the A site in $\mathrm{ABX}_{3}$ structure could further stabilize the perovskite structure [64]. However, $\mathrm{FAPbI}_{3}$ can crystallize into the photo-inactive, non-perovskite hexagonal $\delta$-phase (yellow phase) or photoactive perovskite $\alpha$-phase (black phase) [65] which is sensitive to solvent contamination and humidity [66], therefore posing stability issues.

On the other hand, monovalent cations can also be exchanged with inorganic materials for further improvement so long as they remain within the tolerance factor range. Figure 9 shows the tolerance factor of stable alkali metals $\mathrm{A}=\mathrm{Li}, \mathrm{Na}$, $\mathrm{K}, \mathrm{Rb}$, and $\mathrm{Cs}$ and two additional common monovalent cations MA and FA. The tolerance factor graph depicts that $\mathrm{MAPbI}_{3}, \mathrm{FAPbI}_{3}$, and $\mathrm{CsPbI}_{3}$ fall into the range of 0.8 to 1.0 with a black phase. However, Li-, Na-, and K-based perovskites are undoubtedly outside of the fixed range, where $\mathrm{RbPbI}_{3}$ only lies outside by a small margin. It can also be seen that upon heating $\mathrm{CsPbI}_{3}$, film turns black whereas $\mathrm{RbPbI}_{3}$ remains yellow. Thus, despite its excellent oxidation stability, $\mathrm{Rb}$ alone cannot be used in perovskites. Although $\mathrm{CsPbI}_{3}$ exhibits excellent thermal stability, it does not possess an ideal band gap $(1.73 \mathrm{eV})$ for use in single-junction photovoltaics, and it is unstable in the cubic (or pseudo-cubic) $\alpha$-phase at room temperature [67].

Due to the limitations of pure single cation-single halide perovskite compounds, it has become crucial to design mixed cations/mixed halide perovskites to achieve higher efficiencies and long-term structural and thermal stability. Double cation MA/FA perovskites demonstrate that a small fraction of MA with FA in perovskites offers better crystallization result into photoactive black phases and, consequently, better thermal and structural stability than pure MA or FA perovskites [66, 68]. Recently, Prochowicz et al. demonstrated that the addition of $25 \%$ (molar \%) of MAI to the reaction mixture stabilized the black phase of $\mathrm{FAPbI}_{3}$, and they managed to obtain a PCE of $14.98 \%$ with a high short-circuit current $\left(\mathrm{J}_{\mathrm{SC}}\right)$ density of $23.7 \mathrm{mAcm}^{-2}$ [69].

Besides organic MA/FA-mixed cation-based perovskites, organic-inorganic double cation perovskites have also been explored. Choi et al. reported that $10 \%$ Cs doping in the $\mathrm{MAPbI}_{3}$ perovskite structure resulted in a $40 \%$ enhancement of device efficiency by improving light absorption and morphology, as well an increased energy difference between the valence band of the perovskite and lowest unoccupied molecular orbital (LUMO) level of PCBM [70]. Lee et al. found that the photo and moisture stability of $\mathrm{FA}_{0.9} \mathrm{Cs}_{0.1} \mathrm{PbI}_{3}$ were substantially improved compared to pristine $\mathrm{FAPbI}_{3}$ [71]. Likewise, when MA and FA are used in combination with each other, a small fraction of MA or FA can be replaced with Cs to optimize the optical and electrical properties and further increase device performance. With the goal of improving stability and device performance, Cs was used to explore more complex cation combinations, i.e., $\mathrm{Cs} / \mathrm{MA} / \mathrm{FA}$. The triple-cation (Cs/MA/FA)-based perovskite solar cells with a stabilized PCE of $21.1 \%$ shows more reproducibility and thermal stability than MA/FA double-cation perovskites [67]. Incorporation of $\mathrm{Cs}$ into the MA/FA cation combination helps to dissipate the photo-inactive hexagonal $\delta$-phase of $\mathrm{FAPbI}_{3}$ and the cubic $\mathrm{PbI}_{2}$ completely. Furthermore, adding Cs in variable percentages $(5 \%, 10 \%, 15 \%)$ resulted in a blue shift of $10 \mathrm{~nm}$ for the absorption and photoluminescence (PL) spectra as well as a lower cationic radius, thus allowing the tolerance factor to tend more towards a cubic lattice structure, making the black perovskite phase more entropically stable at room temperature [67]. These results are shown in Fig. 10. Moreover, this significant work opens the door to the incorporation of other oxidation-stable alkali metals like $\mathrm{Li}, \mathrm{Na}, \mathrm{K}$, and $\mathrm{Rb}$ to be explored as the monovalent cations for perovskites.
Fig. 9 Tolerance factor and perovskite films at different temperatures. The tolerance factor of perovskite between 0.8 to 1.0 shows a photoactive black phase (solid circles) where tolerance factor below 0.8 indicates nonphotoactive phase (open circles) [32]

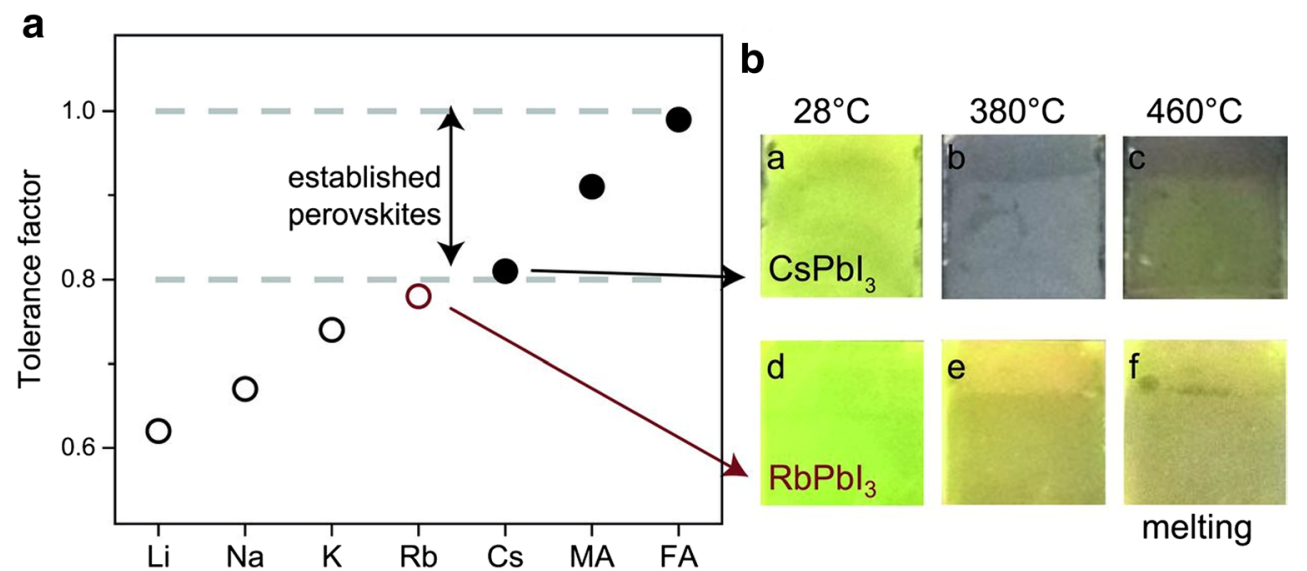




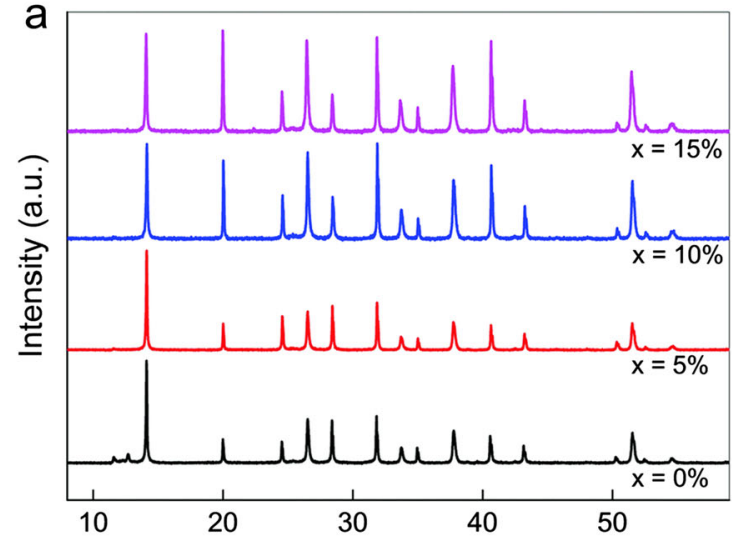

$2 \theta\left({ }^{\circ}\right)$
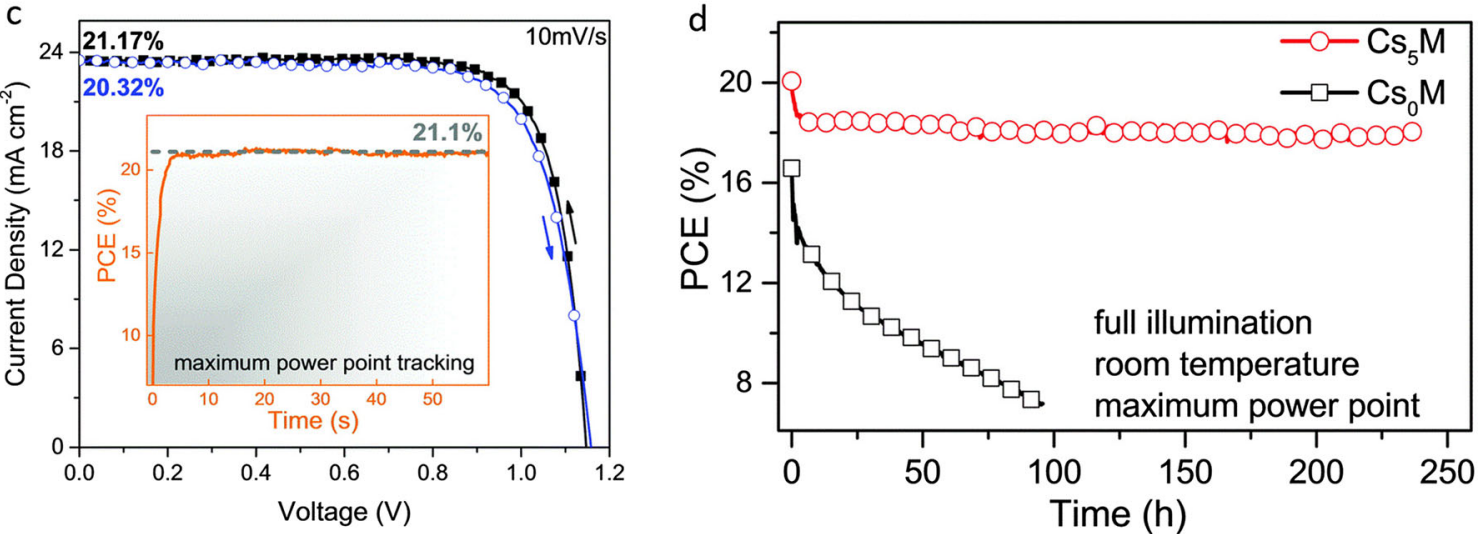

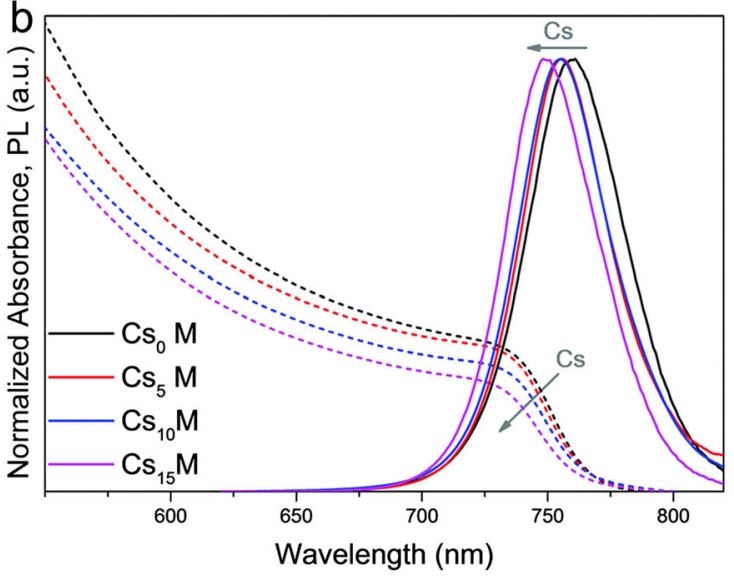

ture

250

Fig. 10 The effects of Cs upon addition in MA/FA cation combination; (a) XRD and (b) optical characterization (c) current-voltage (J-V) and (d) stability characteristics of $\mathrm{Cs}_{\mathrm{x}} \mathrm{MAFA}$ compounds [67]

To explore additional monovalent cations, Saliba et al. recently incorporated $\mathrm{Rb}$ into a photoactive perovskite phase using multiple cation (RbCsMAFA) formulations [32]. They chose alkali metals as the monovalent cations because of their inherent oxidation stability and found that, although the pure $\mathrm{RbPbI}_{3}$ compound is not suitable for use in perovskite solar cells, $\mathrm{Rb}$ can be integrated into multiple cation-based perovskites because $\mathrm{Rb}$ can stabilize the black phase of FA perovskite. They identified different cationic combination such as $\mathrm{RbFA}, \mathrm{RbCsFA}, \mathrm{RbMAFA}$, and RbCsMAFA with consistent device performances compared to previously explored cationic mixture-based perovskites such as CsFA and CsMAFA; specifically, with $5 \% \mathrm{Rb}$ in RbCsMAFA, they achieved a stabilized efficiency up to $21.6 \%$ [32]. These results opened the door to the use of other organic-inorganic cation combination as well as other inorganic cations in perovskite solar cells.

\subsubsection{Halide substitution/mixing}

Halogen ion replacement/mixing can tune the optoelectronic properties of perovskites. The iodine in the lead halide perovskite $\left(\mathrm{MAPbI}_{3}\right)$ structure can be substituted with both chlorine and bromine, and large single crystals have been developed from all three lead halide perovskites; $\mathrm{MAPbCl}_{3}, \mathrm{MAPbBr}_{3}$, and $\mathrm{MAPbI}_{3}$ (Fig. 11).

Liu et al. studied the optical properties (absorption spectrum band gap and photoluminescence spectra) of $\mathrm{MAPbX}_{3}$ $(\mathrm{X}=\mathrm{Cl}, \mathrm{Br}, \mathrm{I})$ as a function of the halogen anions as shown in Fig. 12 [73]. They found that there is a dramatic change in absorbance when the halide substitution occurs between $\mathrm{Cl}$, $\mathrm{Br}$, and I. With an increase in the ionic size of halide, the band gap energy is decreased, for example for a single crystal, the

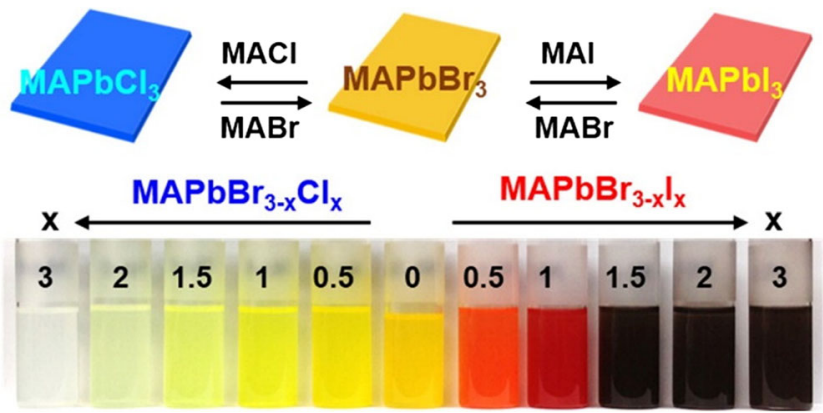

Fig. 11 Photograph of halide substitution/mixing in the perovskite structure [72] 
Fig. 12 Effects of halide substitution on optoelectronic properties of perovskite: absorption spectrum, band gap, and photoluminescence spectrum [73]
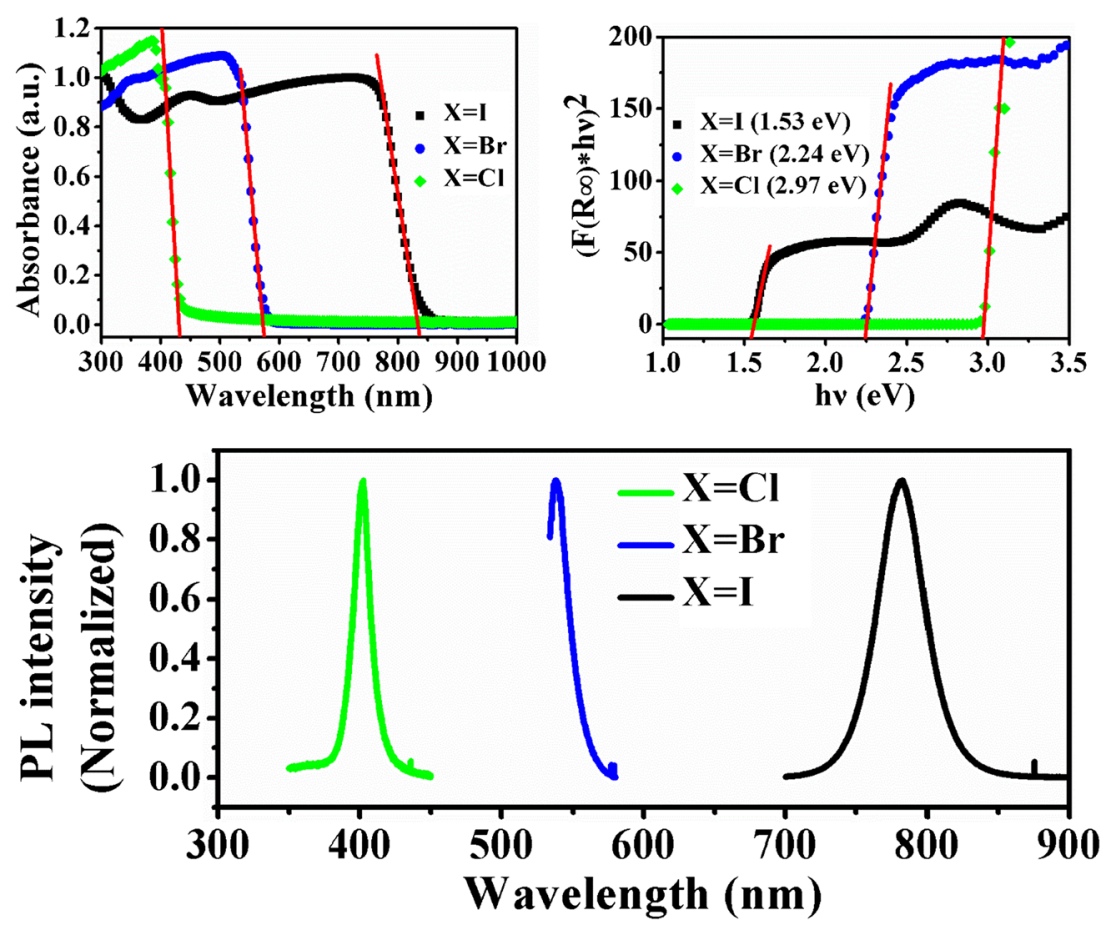

band gap is $2.97,2.24$, and $1.53 \mathrm{eV}$ for the $\mathrm{Cl}, \mathrm{Br}$, and $\mathrm{I}$ perovskite, respectively [73]. Moreover, the smaller PL peak values compared to the absorption onsets make them advantageous to be applied in solar cells [73].

From the photovoltaic perspective, each perovskite structure has certain benefits. For example, $\mathrm{MAPbI}_{3}$ and $\mathrm{MAPbBr}_{3}$ are suitable for single band gap absorbers and tandem applications respectively whereas $\mathrm{MAPbCl}_{3}$ is more useful for light-emitting devices [68]. However, mixing halides in perovskites can have additional beneficial effects, for examplestability, enhancing carrier transport, and band gap tuning. Lee et al. found that mixed halide perovskite $\mathrm{MAPb}\left(\mathrm{I}_{1-\mathrm{X}} \mathrm{Cl}_{\mathrm{X}}\right)_{3}$ had a stability advantage over $\mathrm{MAPbI}_{3}$ during processing in the air [26]. Noh et al. confirmed that mixing 20-29\% $\mathrm{Br}$ into $\mathrm{MAPbI}_{3}$ significantly enhanced the stability of the produced solar cells while maintaining the cell's efficiency [12]. In addition, $\mathrm{MAPb}\left(\mathrm{I}_{1-\mathrm{X}} \mathrm{Cl}_{\mathrm{X}}\right)_{3}$ also had longer electron-hole diffusion lengths than $\mathrm{MAPbI}_{3}$, while the other two forms of mixed halide perovskites $\mathrm{MAPb}\left(\mathrm{I}_{1-\mathrm{X}} \mathrm{Br}_{\mathrm{X}}\right)_{3}$ and $\mathrm{MAPb}\left(\mathrm{Br}_{1-\mathrm{X}} \mathrm{Cl}_{\mathrm{X}}\right)_{3}$ exhibited increased carrier mobility and reduced carrier recombination rates $[74,75]$. However, it is hard to form mixed (I, Cl) perovskite at a temperature below $625 \mathrm{~K}$, while it is simple to form mixed $(\mathrm{Br}, \mathrm{Cl})$ and $(\mathrm{I}, \mathrm{Br})$ perovskite at room temperature [76]. Therefore, $\mathrm{I} / \mathrm{Br}$-halide combination appears to be more promising for overall performance.

It is also possible to design a mixed cation and halide perovskite solar cell by combining the benefits of the constituents and avoiding their disadvantages. Jeon et al. showed $\left(\mathrm{FAPbI}_{3}\right)_{0.85}\left(\mathrm{MAPbBr}_{3}\right)_{0.15}$ has many advantages over other systems such as $\mathrm{MAPbI}_{3}, \mathrm{FAPbI}_{3}$, and $\mathrm{MAPb}\left(\mathrm{I}_{0.85} \mathrm{Br}_{0.15}\right)_{3}$
[66]. However, the composition management of different components of perovskite is still an ongoing research. Jacobsson et al. showed that a small change in the chemical composition has a significant impact on the properties of the materials as well as the device performance and they managed to increase the PCE up to $20.7 \%$ for a double-cation doublehalide mixed perovskite solar cell [77]. In addition, as already discussed in the previous section, researchers are incorporating more cations (triple, quadruple) with the mixed halide in the perovskites to have more efficiency and stability $[31,32]$.

\subsection{Divalent metal cation exchange/mixing}

Although the efficiency of lead-based perovskites has been steadily enhanced over the last few years, the toxicity of lead still hinders commercialization efforts and is still an unsolved drawback. Moreover, from both a toxicological and environmental perspective, it is essential to replace lead and find less toxic/non-toxic functional materials which help to increase the efficiency and stability of perovskites. Much research has been done with a few different elements that could potentially substitute for lead, including $\mathrm{Sn}, \mathrm{Ge}, \mathrm{Cu}, \mathrm{Sb}, \mathrm{Bi}$, and $\mathrm{Sr}$ [78-83]. Among them, Sn-based perovskites $\left(\mathrm{MASnI}_{3}\right)$ have achieved an efficiency of up to $6 \%$ [78]. However, Sn-based perovskites are prone to self-doping effects and structural instabilities, e.g., they can oxidize from $\mathrm{Sn}^{2+}$ to $\mathrm{Sn}^{4+}$. Subsequently, perovskites based on Sn tend to degrade rapidly upon exposure to ambient air. Recently, $\mathrm{Pb}-\mathrm{Sn}$ binary perovskites have become very promising due to their reduced toxicity and enhanced performance. Several efforts have been 
made with chemical composition management of $\mathrm{Pb}$ and $\mathrm{Sn}$ and optimization of the fabrication process [84-86], and recent breakthroughs have been reported to yield a PCE of $15.08 \%$ with good reproducibility [87].

Germanium $(\mathrm{Ge})$ is another potential candidate to serve as the divalent metal cation in perovskite structure. Computational screening based on density-functional-theory (DFT) calculations suggested that Ge would be a good candidate element for replacing $\mathrm{Pb}$ [88]. However, Ge-based perovskites have not yielded any decent results until recently. Krishnamoorthy et al. demonstrated G-based perovskite solar cells which had very poor open-circuit voltages and a maximum PCE of $0.20 \%$ [79]. Furthermore, Kopacic et al. modified the perovskite composition by introducing bromide ions into the methylammonium germanium perovskite (MAGeI ${ }_{2.7} \mathrm{Br}_{0.3}$ ), and they obtained a maximum PCE of $0.57 \%$ with a planar p-i-n device configuration [89]. Researchers are also trying to replace lead with cations other than group 14 elements. Recently, Shai et al. developed a binary $\mathrm{Pb}-\mathrm{Sr}$-based PSC which achieved a PCE of $16.3 \%$ after integration of a small amount of $\operatorname{Sr}(a \leq 0.05)$ into the $\mathrm{MASr}_{\mathrm{a}} \mathrm{Pb}_{1-\mathrm{a}} \mathrm{I}_{3-\mathrm{x}} \mathrm{Cl}_{\mathrm{x}}$ crystal lattice [90].

Apart from the best material choice, it is also essential to obtain a high-quality perovskite film. Different firm-forming methods have been developed such as spin coating [91], doctor blade [92], dip coating [93], slot-die coating [94], spray coating [95], inkjet printing [96], vapor-based deposition [97] etc. Among different film-forming methods, spin coating is the most popular and extensively used in the lab-scale perovskite solar cell fabrication process. This method offers the advantages to deposit thin films with well-defined and uniform thickness [98]. However, it is not suitable for largescale PSC fabrication. Also, materials are wasted during the spin-coating process, which increases the fabrication cost of PSCs. Doctor blade techniques offer simple and low-cost film formation, as well as material waste, is almost negligible unlike spin coating [99]. However, it is difficult to control the thickness of the film through this method. Slot-die coating is recently introduced in perovskite solar cell [100]. Using this method, Qin et al. obtained a PCE of $14.7 \%$ with an active area of $10 \mathrm{~mm}^{2}$ [101]. However, it is also hard to make thin film through this method. Although spray-coating technique offers low cost on the large-scale fabrication of PSCs, the film quality is not very good due to the poor film uniformity and steadiness [39]. Ink-jet printing is another suitable method to form thin films with great precision and good controllability. This method is a cost-effective method due to the negligible material waste during fabrication [96]. In general, all these non-vacuum-based techniques could be considered as the alternative to the spin-coating technique for fabrication of PSCs. However, the poor control of surface morphology of perovskite is a disadvantage of these methods, which would affect the performance of the PSC devices [46].

\subsection{Electron-transporting materials}

The optimization of the electron-transporting material (ETM) is crucial for improving PSC performance. Both organic and inorganic materials can be used as an ETM in PSCs; typically, inorganic materials are used in the regular device architecture whereas organic materials are used in the inverted device architecture. In the following two subsections, we summarize the recent research efforts and advancements related to both inorganic and organic electron transport materials. Several characteristics are required of an ideal ETM: it must have an energy level that is compatible with that of the perovskite material to help promote injection of the photo-generated electrons and reduce energy losses, and it must possess innately high electron mobility to enable fast electron transport [102]. The energy levels of some common organic and inorganic ETLs used in perovskite solar cells are shown in Figs. 13 and 14.

\subsubsection{Inorganic}

Most photovoltaic solar cells employ transition-metal oxides as the electron transport layer (ETL), which acts as a selective contact for electron transportation to the anode. At present, titanium dioxide $\left(\mathrm{TiO}_{2}\right)$ is the most commonly used ETL in the conventional n-i-p PSC architecture; since $\mathrm{TiO}_{2}$ has excellent electron-transporting properties. However, because of the traditional high-temperature $\left(\sim 500^{\circ} \mathrm{C}\right)$ sintering manufacturing process used to create the $\mathrm{TiO}_{2}$ layer, certain temperaturesensitive materials, and device architectures are necessarily excluded when this process is used [103]. Thus, the development of a simple low-temperature process for generating the $\mathrm{TiO}_{2}$ layer is vital for the fabrication of low-cost solar cells and exploration of cell architectures based on temperaturesensitive materials. Coning et al. developed a lowtemperature sol-gel process to prepare $\mathrm{TiO}_{2}$ nanoparticles for the ETL and were able to obtain a PCE of $13.6 \%$ [104]. However, this result was highly dependent on the thermal history of the $\mathrm{TiO}_{2}$. Yella et al. also established a lowtemperature fabrication process utilizing nanocrystalline rutile $\mathrm{TiO}_{2}$ deposited through a chemical bath deposition method, and they managed to obtain a PCE of $13.7 \%$ with a $\mathrm{V}_{\mathrm{OC}}$ of $1.1 \mathrm{~V}$, notably higher than that of the device prepared with planar $\mathrm{TiO}_{2}$ which only yielded a PCE of $3.7 \%$ [105]. As another major advancement in the fabrication process of $\mathrm{TiO}_{2}$-based ETLs, Petrozza et al. demonstrated the use of low temperature $\left(<100{ }^{\circ} \mathrm{C}\right)$ solution-processed $\mathrm{TiO}_{\mathrm{x}}$ as an ETL in PSCs and were able to obtain a PCE as high as $17.6 \%$ [106]. Though they used an additional interfacial layer with $\mathrm{TiO}_{2}$, the efficiency was still high for devices prepared without the interfacial layer. Under UV light, it has been found that $\mathrm{TiO}_{2}$ ETM-based solar cells can suffer from reduced stability $[107,108]$, which may be a challenge towards the commercialization of $\mathrm{TiO}_{2}$-based solar cells. However, utilizing a 
Fig. 13 Energy levels of different materials acting as inorganic ETM with varying layers of perovskite solar cell

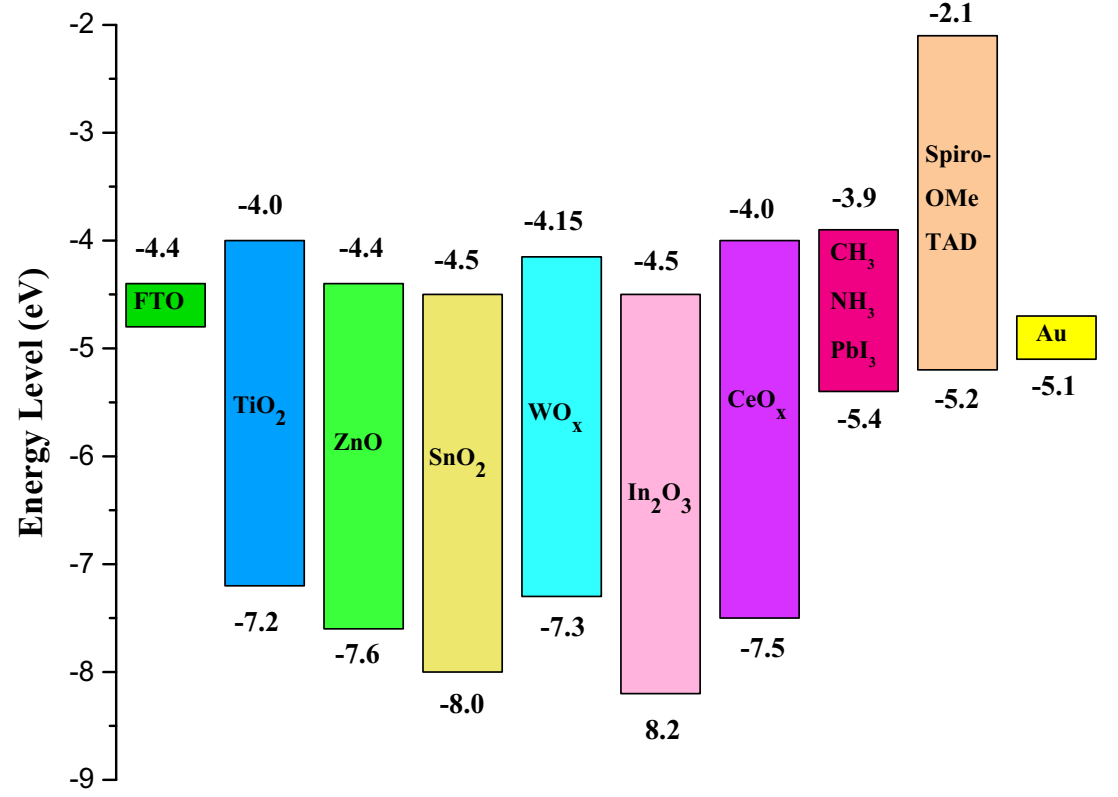

down-conversion layer could be a possible solution to reduce the UV degradation for PSCs. Jiang et al. used a transparent luminescent down-converting layer of Eu-complex (Eu-4,7diphenyl-1, 10-phenanthroline) to enhance the light utilization and found that incorporating an Eu-complex layer helped to enhance $11.8 \%$ short-circuit current density and $15.3 \%$ efficiency due to the re-emitting UV light (300-380 nm) in the visible range compared with the uncoated any downconversion layer [109]. Moreover, although the electron injection rate from the photoactive perovskite to the $\mathrm{TiO}_{2} \mathrm{ETL}$ is very fast, this is offset somewhat by high electron recombination rates because of low electron mobility [110]. Thus, there is much interest in exploring other inorganic ETMs to further increase the PCE and stability of PSCs.
In comparison with $\mathrm{TiO}_{2}, \mathrm{ZnO}$ shows higher electron mobility (bulk mobility, 205-300 $\mathrm{cm}^{2} \mathrm{~V}^{-1} \mathrm{~s}^{-1}$ ) and can be easily generated via a low-temperature process which requires no heating or sintering [111]. Therefore, these benefits make $\mathrm{ZnO}$ as an ideal candidate for an electron selective contact/ ETL. Son et al. utilized ZnO nanorods as an ETL and obtained a PCE of $11.13 \%$, whereas Liu et al. utilized $\mathrm{ZnO}$ nanoparticles and managed to obtain a PCE as high as $15.7 \%$ [112, 113]. However, $\mathrm{ZnO}$ is also known to be chemically unstable and, therefore, is potentially detrimental to the long-term stability/commercialization efforts of PSCs [114].

Recently, $\mathrm{SnO}_{2}$ has been evaluated as another promising ETM due to its wide band gap, high transparency, and high electron mobility. Li et al. successfully employed a $\mathrm{SnO}_{2}$
Fig. 14 Energy levels of various materials working as organic ETM with different layers of perovskite solar cell

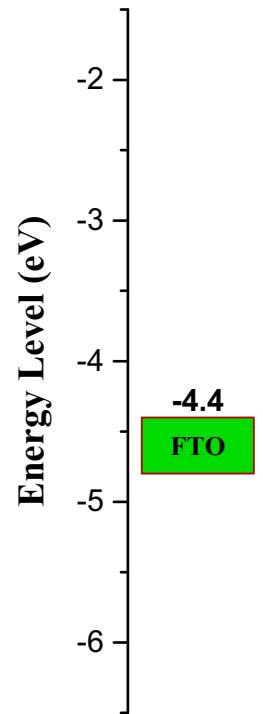

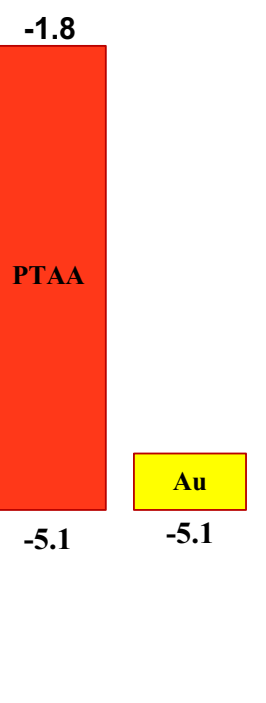


nanoparticle film as an ETL/scaffold layer (to replace the traditional mesoporous $\mathrm{TiO}_{2}$ film), and they managed to achieve an efficiency exceeding $10 \%$ [115]. Song et al. demonstrated that using low-temperature-processed $\mathrm{SnO}_{2}$ as an ETL in a basic planar PSC architecture could yield PCEs of up to $13.0 \%$, with remarkable stability when exposed to the ambient air/environment for up to 30 days [116]. Ke et al. fabricated a $\mathrm{SnO}_{2}$ ETL layer with excellent optical and electronic properties using a low-temperature sol-gel method followed by annealing at $180^{\circ} \mathrm{C}$, and they managed to obtain a power conversion efficiency of $17.21 \%$ [117].

Although $\mathrm{SnO}_{2}$ possesses excellent optical and electrical properties and can be prepared via a low-temperature solutionbased technique, the notable hysteresis observed in devices utilizing $\mathrm{SnO}_{2}$ as an ETL is a hindrance of $\mathrm{SnO}_{2}$-based PSC devices. In order to overcome this problem, Baena et al. deposited a 15-nm-thick $\mathrm{SnO}_{2}$ electron-selective layer (ESL) through a lowtemperature atomic layer deposition (ALD) technique and achieved a barrier-free band alignment between the $\mathrm{SnO}_{2}$ and the mixed perovskite $\left(\left(\mathrm{FAPbI}_{3}\right)_{0.85}\left(\mathrm{MAPbI}_{3}\right)_{0.15}\right)$ materials, creating a highly efficient/almost hysteresis-free planar PSC with an open-circuit voltage of $1.19 \mathrm{~V}$ and PCE over 18\% [30]. These results are displayed in Fig. 15. In 2016, the same group demonstrated a simple, fast, and low-temperature technique to deposit $\mathrm{SnO}_{2}$ by combining spin coating (SC) (Fig. 16a) with a chemical bath deposition (CBD)-based post-treatment (Fig. 16b), and they found a further reduction in hysteresis and excellent stability with an obtained PCE of 21\% [31]. By utilizing the CBD technique, the roughness and uniformity of the ETL were improved, and consequently, the blocking capabilities of the $\mathrm{SnO}_{2}$ layer were improved (Fig. 16e) [31].

Indium oxide $\left(\mathrm{In}_{2} \mathrm{O}_{3}\right)$ is another promising n-type material which possesses excellent optical and electrical properties including a wide band gap, high electron mobility, and good light-transmitting properties. Utilizing these advantages, Fang et al. employed a low-temperature solution-processed $\mathrm{In}_{2} \mathrm{O}_{3}$ nanocrystalline film as an ETL in PSCs for the first time and achieved an efficiency exceeding $13 \%$ [118]. a
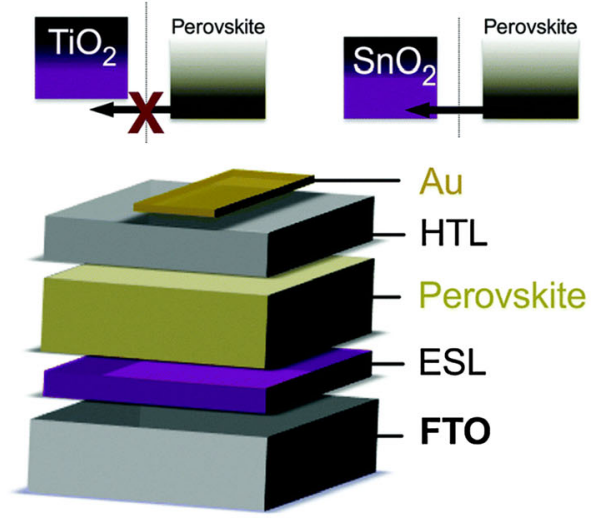

b

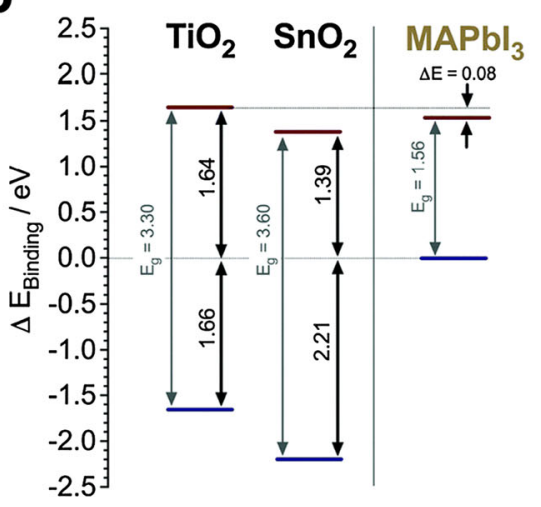

C

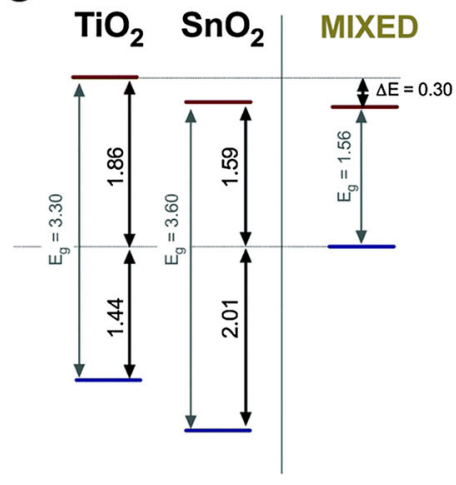

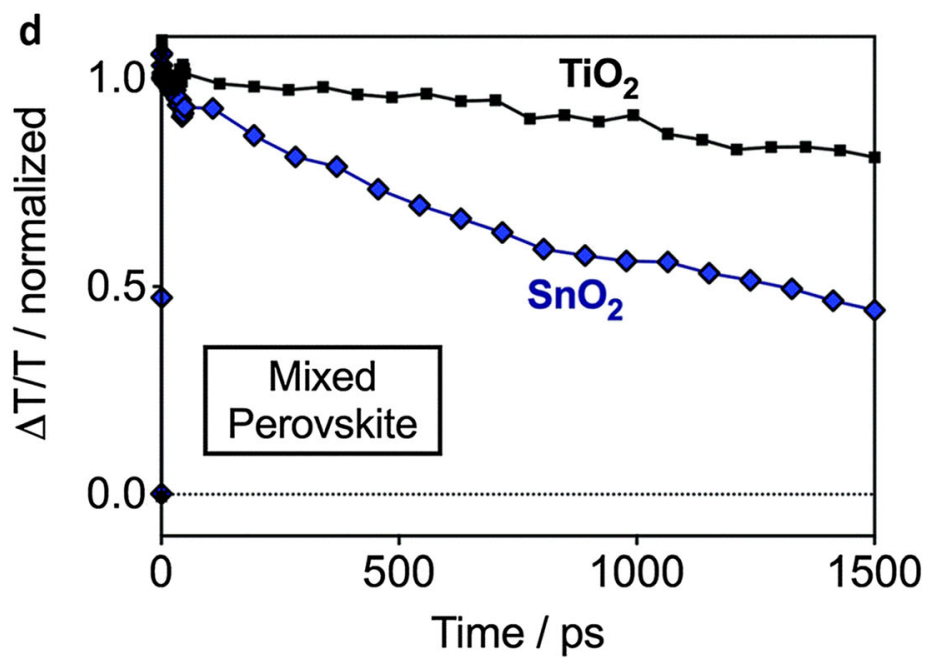

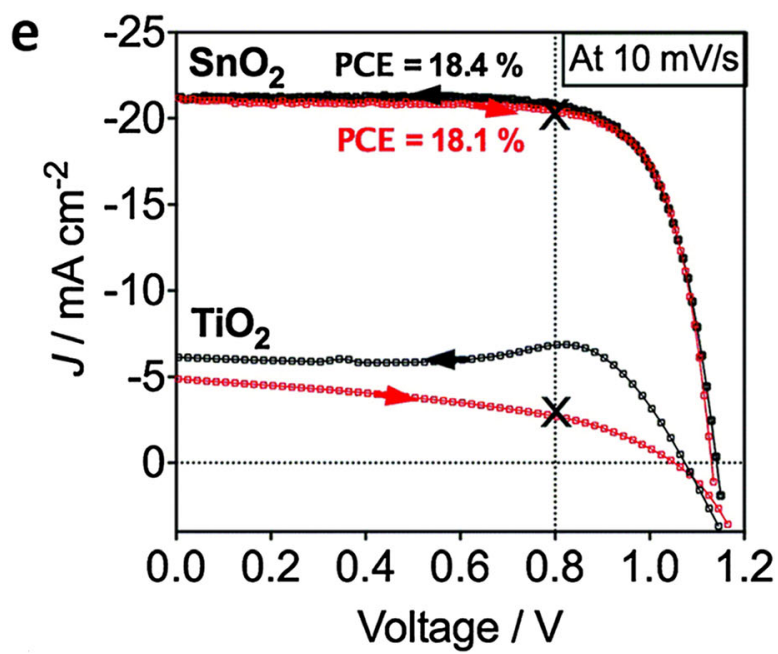

Fig. 15 (a-c) Schematic of energy level diagrams and electron injection characteristics of $\mathrm{SnO}_{2}-$ and $\mathrm{TiO}_{2}$-based planar PSCs, (d) Transient absorption measurements, (e) Current-voltage $(\mathrm{J}-\mathrm{V})$ properties of $\mathrm{TiO}_{2}$ - and $\mathrm{SnO}_{2}$-based planar mixed halide--mixed cation perovskite solar cell devices [30] 
Fig. 16 Schematic illustrations of the fabrication of $\mathrm{SnO}_{2}$ thin films via (a) spin coating (SC) and (b) chemical bath deposition (CBD). Top-view SEM images of $\mathrm{SnO}_{2}$ layers deposited by $\mathbf{c}$ atomic layer deposition (ALD), (d) spin coating (SC), and (e) spin coating and chemical bath deposition (SC-CBD). All scale bars are $200 \mathrm{~nm}[31]$ a

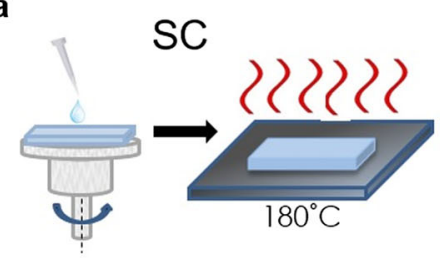

b

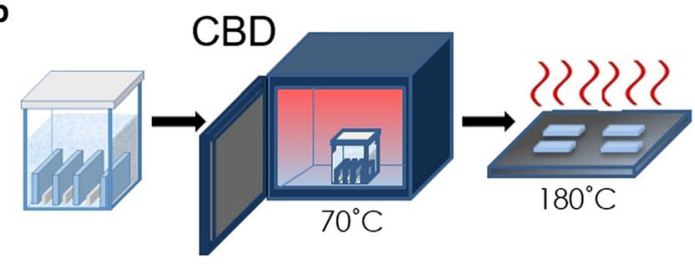

C

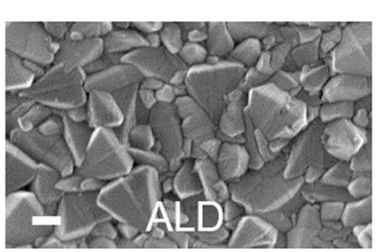

d

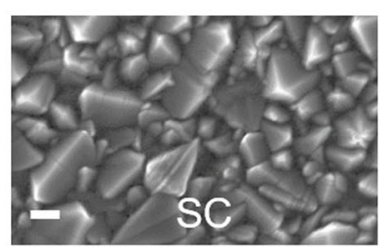

e

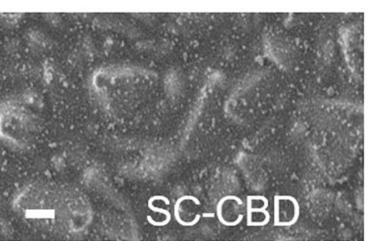

WOx is another possible potential n-type material for ETLs which has good chemical stability, a wide band gap, and high electron mobility. Wang et al. applied $\mathrm{WO}_{\mathrm{X}}$ as an electronselective layer in PSCs through a simple, low-temperature solution process which exhibited comparable light transmittance and photoelectric conversion efficiency to $\mathrm{TiO}_{2}$, but with higher electric conductivity as well as short-circuit current density; however, they obtained a lower open-circuit voltage [119].

Because of some excellent properties such as wide band gap and high thermal and chemical stability, $\mathrm{CeO}_{\mathrm{x}}$ is also being considered as a promising material for ETLs. Though $\mathrm{CeO}_{\mathrm{x}}$ has already been used in different solar cells for its outstanding properties, Wang et al. reported using $\mathrm{CeO}_{\mathrm{x}}$ as an ETL material in PSCs for the first time in 2017 [120]. They demonstrated that solution-processed $\mathrm{CeO}_{\mathrm{x}}(x=1.87)$ based PSCs could be prepared via a facile, simple sol-gel method at a low temperature $\left(150^{\circ} \mathrm{C}\right)$, as a possible alternative to high-temperature sintering-processed $\mathrm{TiO}_{2}$-based PSCs. The $\mathrm{CeO}_{\mathrm{x}}$-based planar PSCs achieved a PCE as high as $14.32 \%$ with good stability [124].

\subsubsection{Organic}

Organic n-type materials such as fullerenes $\left(\mathrm{C}_{60}\right)$ and their derivatives (including [6,6]-phenyl-C61-butyric acid methyl ester $\left(\mathrm{PC}_{61} \mathrm{BM}\right)$, indene $\mathrm{C} 60$ bis-adduct (ICBA), and [6,6]phenyl-C71-butyric acid methyl ester $\left(\mathrm{PC}_{71} \mathrm{BM}\right)$ ) have seen very widespread use as ETLS in inverted-architecture perovskite solar cells due to their good band gap alignment, sufficient electron mobility, and amenability to a low-temperature solution-based deposition process. PCBM has high electrical conductivity and has been the most commonly used PSC ETL material of the fullerene derivatives. It has been shown to efficiently quench the photoluminescence of $\mathrm{MAPbI}_{3}$, lending it a high probability of efficient charge transfer [121]. Jeng et al. tested different fullerene derivatives as ETMs in inverted planar PSCs and found that devices with $\mathrm{PC}_{61} \mathrm{BM}$ outperformed those prepared with $\mathrm{C}_{60}$ and ICBA [43]. Some of the common organic electron-transporting materials and a comparison of their energy levels with the energy levels of the other component layers of PSCs are shown in Fig. 14. The LUMO energy level of $\mathrm{C}_{60}$ compared to $\mathrm{PC}_{61} \mathrm{BM}(4.5 \mathrm{eV}$ vs. $3.9 \mathrm{eV}$ ) explains the $\mathrm{V}_{\mathrm{OC}}$ drop in PSC devices prepared with $\mathrm{C}_{60}$, whereas cells prepared with ICBA (which has a higher LUMO energy level than $\mathrm{PC}_{61} \mathrm{BM}$ ) yield a higher $\mathrm{V}_{\mathrm{OC}}$ [43]. Wang et al. also observed similar results regarding the photovoltage in planar PSC devices [122]. Other than the fullerene derivatives, there are other organic materials that have been evaluated as ETLs in inverted PSC architectures. For example, Malinkiewicz et al. demonstrated that organoborane compounds like 3TPYMB could be suitable as an ETL material for inverted PSCs [123]. They found that 3TPYMB-based PSCs achieved a PCE of 5.5\% which compares somewhat favorably with expensive PCBM-based devices which exhibited $10 \%$ PCE [123].

\subsection{Hole-transporting materials}

The choice of hole-transporting material plays a significant role in determining the performance of PSCs. The primary functions of HTMs are to act as a hole-selective contact, to extract the photo-generated holes, and to carry the holes to the metal contact. By obstructing the direct contact between the counter electrode and the perovskite/photoactive layer, the ETL prevents charge recombination and increases overall PCE [124]. An ideal HTM should have some basic characteristics, including a well-matched highest occupied molecular orbit (HOMO) energy level relative to the perovskite layer for efficient interfacial hole transfer, good internal hole mobility, and good thermal and photochemical stability [125]. The different classes of HTMs (e.g., small molecules, polymeric, inorganic) have benefits and drawbacks. A comparison of the energy levels of different HTM with the other functional layers of PSCs is presented in Fig. 17. In the following subsections, we will discuss the recent advancements made towards the development of an ideal HTM for perovskite solar cells. 
Fig. 17 Energy levels of different materials acting as HTM with different layers of perovskite solar cell

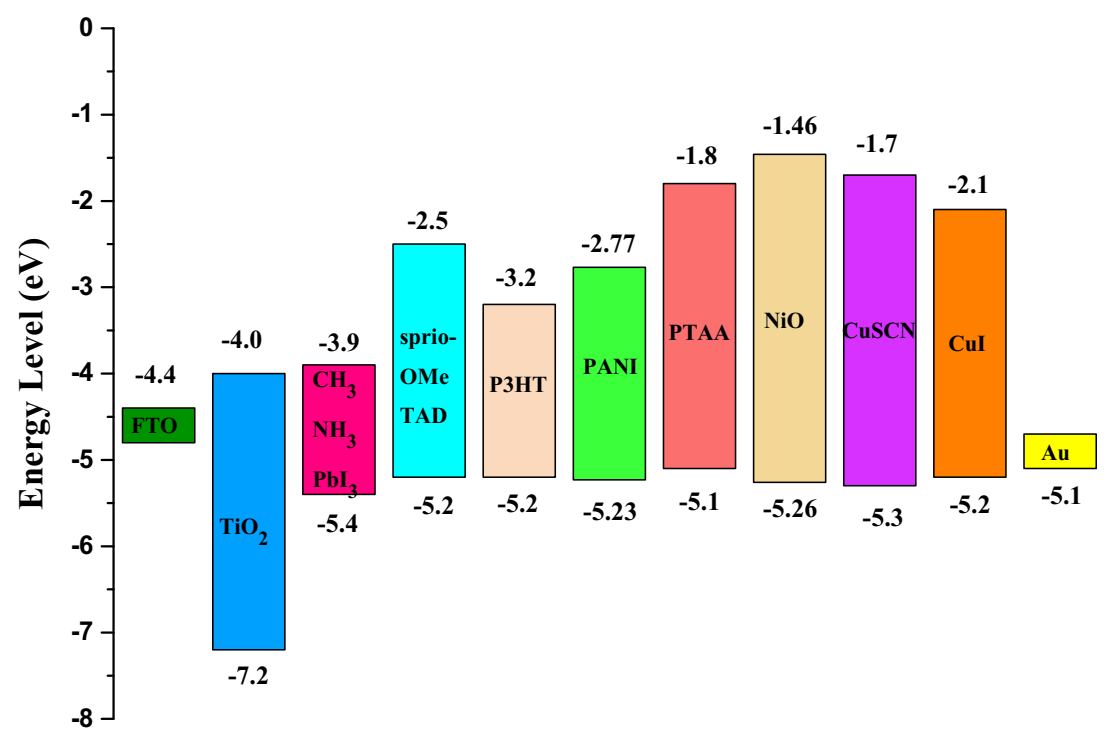

\subsubsection{Small molecules}

Small molecules have been extensively used as HTMs due to their relatively simple processing and extensive modifiability. Among the different small molecules tested as HTMs for PSCs, Spiro-OMeTAD has been the most commonly used HTM in PSCs. Besides efficiently transporting holes to the counter electrode, it has also been shown to minimize the series resistance as well as interfacial recombination losses in PSCs, thereby helping to increase the fill factor (FF) and open-circuit voltage $\left(\mathrm{V}_{\mathrm{OC}}\right)$ of the PSCs [22]. Although SpiroOMeTAD HTM-based PSCs have enhanced PCEs, the high cost due to the lengthy and low-yielding synthetic method for Spiro-OMeTAD remains a significant barrier for the commercialization of PSCs. Furthermore, the addition of ionic additives such as bis(trifluoromethane)sulfonimide lithium salt (Li-TFSI) and 4-tert-butyl pyridine (TBP) and co-dopants are required to improve the innate conductivity and hole mobility of Spiro-OMeTAD [126], which further increases the fabrication cost of Spiro-OMeTAD-containing PSCs.

\subsubsection{Polymer}

Polymeric HTMs have been considered as a potentially cheaper alternative to small-molecule HTMs. Polymers such as polyaniline (PANI), poly(triarylamine) (PTAA), and poly(3-hexylthiophene-2,5-diyl) (P3HT) offer higher hole mobility than the small-molecule HTMs and, also typically, have excellent film-forming properties due to their polymeric nature [127]. Heo et al. reported that PTAA yielded a significantly higher PCE (12\%) compared to P3HT (6.7\%) [128]. Although at the early stages P3HT-based PSCs exhibited lower efficiencies due to the high rates of charge recombination compared to other HTMs (like Spiro-OMeTAD) [129], recently, P3HT HTM-based PSC devices have shown competitive efficiencies with carefully controlling the thickness of P3HT to avoid problems associated with voltage loss and high resistance [130, 131]. Xion et al. demonstrated that PANI could act as both the sensitizer and the hole-transporting material in PSCs and reported a PCE of 7.34\% as well as excellent long-term stability [132].

\subsubsection{Inorganic}

Inorganic materials have also been explored as HTMs due to their intrinsically high stability, high internal charge mobility, and generally low cost [129]. However, the solvents typically used to deposit the inorganic HTMs can partially dissolve or degrade the perovskite material and, therefore, have a detrimental impact on PCE performance/stability of n-i-p structure PSC [133]. Another reason for the slow progress towards the development of inorganic HTMs for PSCs is the relatively limited choice of materials compared to the other classes of HTMs. However, many different inorganic materials have been investigated as HTMs, including $\mathrm{CuI}$ (PCE 14.7\%) [134], $\mathrm{NiO}$ (PCE 12.5\%) [135], and CuSCN (PCE 17.5\%) [136]. The CuI HTM-based PSCs showed low open-current voltage which can be attributed to higher recombination losses, as was determined via impedance spectroscopy [137]. Optimization of the thickness of the HTL is a promising way to improve the performance of PSC devices. Qin et al. optimized the thickness of a CuSCN-based HTL and were able to achieve a PCE of $12.4 \%$ as well as a high short-circuit current due to the enhanced charge extraction from the perovskite and efficient hole transportation to the cathode [138]. Chen et al. found that film thickness of $\mathrm{NiO}_{\mathrm{x}}$ HTL plays a crucial role in device performance, and with adequate oxygen flow doping of $10 \%$, they managed to improve the performance of hole extraction/electron blocking layer achieving a PCE of $11.6 \%$ [139]. 


\subsection{Carbon nanotubes in perovskite solar cells}

Research on carbon-based materials for photovoltaic devices has shown remarkable development in recent years. Carbon nanotubes (CNT) have a variety of industrial and scientific applications due to their excellent charge transport characteristics, chemical inertness, and mechanical robustness [140]. When applied to PSCs, they have been shown to be able to both efficiently extract the photo-generated charges and to improve the overall resiliency and stability of the solar cells [141]. Depending on the synthetic method/resulting morphology of the tubes, CNT can be classified as single-walled carbon nanotubes (SWCNTs), double-walled carbon nanotubes (DWCNTs), or multi-walled carbon nanotubes (MWCNTs).

Chen et al. developed P3HT/MWCNT composite HTMbased PSCs which showed enhanced PCE (6.45\%) compared to similar cells with a plain P3HT HTM layer [142]. MWCNT inclusion in the P3HT/MCWNT composite led to the formation of efficient nanostructured charge transport tunnels, which increased the conductivity of the composite as well as the fill factor of the cell. In 2014, Habisreutinger et al. demonstrated an effective method to alleviate the thermal stability issues of PSCs by substituting organic HTMs with polymer-functionalized SWCNTs, and they were able to obtain a maximum PCE of 15.3\% [143]. In 2016, Aitola et al. investigated SWCNT and an SWNCT: Spiro-OMeTAD composite as the both HTM and counter electrode (CE) [144]. The PSCs utilizing the composite SWCNT: Spiro-OMeTAD as the HTM-CE yielded a maximum efficiency of $15.5 \%$, whereas the PSCs utilizing SWCNTs as the HTM-CE yielded a maximum PCE of $11.0 \%$ [144]. It is wellknown that perovskite also transports holes [145]. Aitola et al. also compared SWCNT with Au as HT-CE materials and found that SWCNT deployed as both HTM-CE yielded better performing PSCs than Au deposited directly on perovskite layer acting as both HTM-CE [144]. These findings prove that SWCNT helps to improve hole extraction and transportation in PSC devices. The fabrication process of hybrid SWCNT and drop-cast Spiro-OMeTAD-based PSC are shown in Fig. 18a and the result obtained from the comparative study are shown in the Fig. 18b. Therefore, carbon nanotubes are demonstrably capable of fulfilling multiple roles in PSCs including that of the hole transport material, acting as an interface modifier between the HTM and perovskite and acting as a charge-selective electrode [141]. Further improvement of power conversion efficiency through the use of carbon nanotubes in various roles within PSCs make CNT-based PSCs an important area of research.

\section{Fiber-type perovskite solar cells}

With the ever-increasing importance of electronics in modern society, wearable/portable electronics are becoming an essential part of our daily life. Consequently, the incorporation of flexible optoelectronic devices into clothing, backpacks, and other common flexible objects will be important to fulfill the demand for the next-generation smart products, namely etextiles [146]. In particular, flexible fiber/wire-shaped energy-generating devices will play a crucial role in the production of practical e-textiles like wearable solar power sources for self-powered textile-based electronics. Devices fabricated on conductive fiber or wire-type substrates will be suitable for contexture/incorporation into textile materials. However, existing solar cells are mainly based on rigid substrates, for example - fluorine-doped tin oxide (FTO) or indium tin oxide (ITO)-coated glass substrates. The rigidity, weight, and frangibility of these traditional substrates limit the integration potential of PSCs based on them into portable and wearable electronics [147]. a
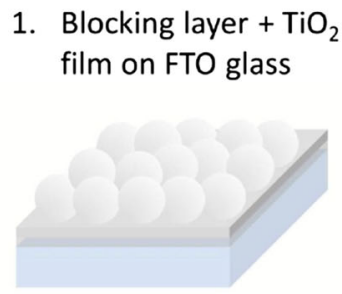

3. SWCNT film transfer

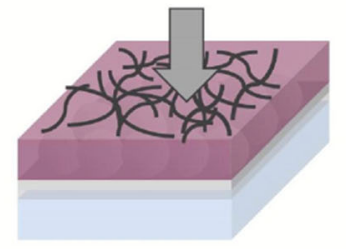

2. $\left(\mathrm{FAPbl}_{3}\right)_{0.85}\left(\mathrm{MAPbBr}_{3}\right)_{0.15}$ spin-coating

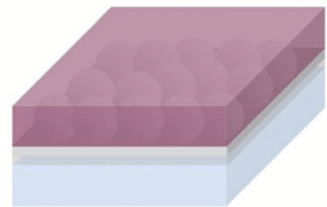

4. Spiro-OMeTAD drop-casting

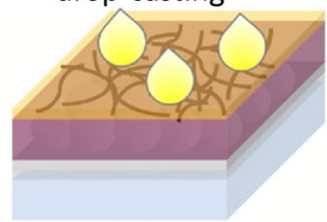

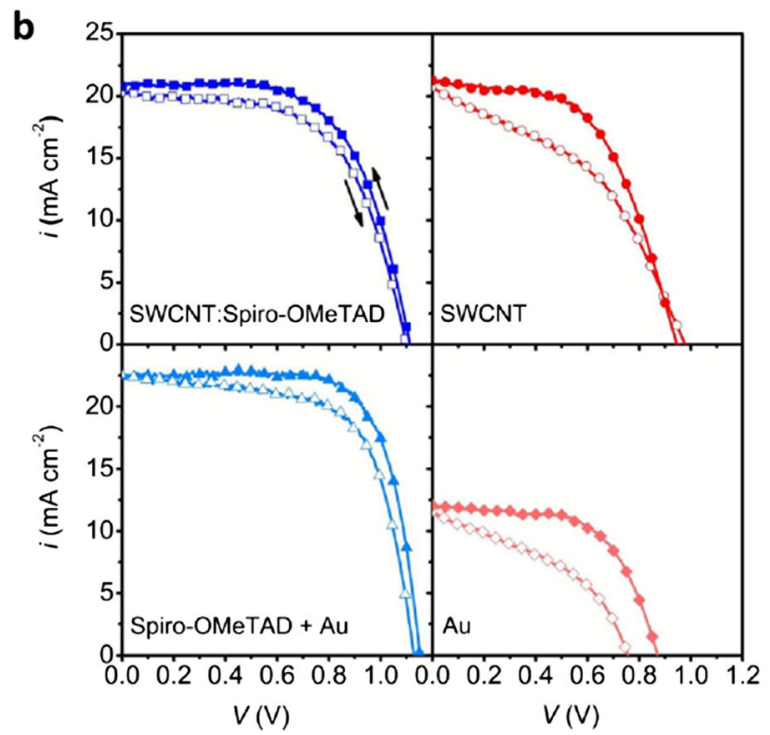

Fig. 18 (a) Fabrication sequence of a hybrid hole-selective electrode on a mixed perovskite absorber composed of SWNTs and Spiro-OMeTAD; (b) the current-voltage characteristics of this structure is compared to Spiro-OMeTAD + gold, SWNTs, and gold only, showing that the combination of SWNTs and Spiro-OMeTAD improves device performance compared to just SWNTs and gold [144] 


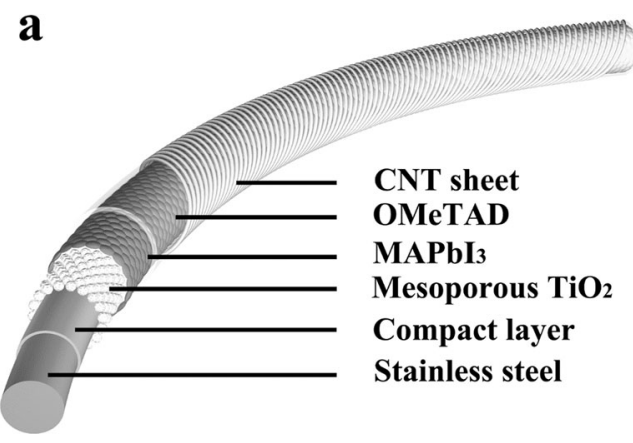

b

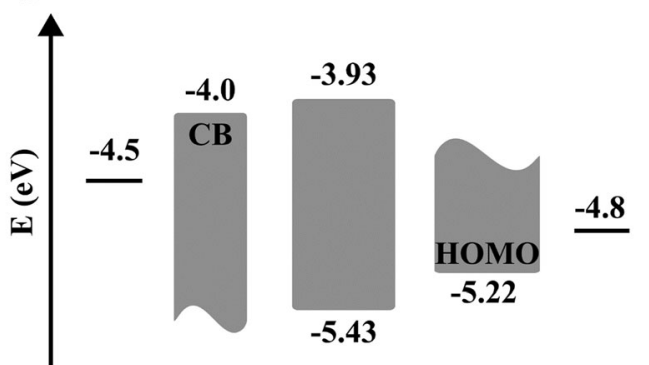

SS $\mathrm{TiO}_{2} \quad \mathrm{MAPbI}_{3}$ OMeTAD CNT

Fig. 19 Schematic representation of the structure of a fiber-shaped PSC: (a) structure - stainless steel (SS) as anode and carbon nanotube (CNT) as the cathode and (b) energy-level diagram [148]

Fiber-shaped perovskite solar cells could be potential candidates for inclusion into the next generation of wearable/ portable electronics. Peng et al. first developed fiber-shaped PSCs utilizing a transparent MWCNT sheet as the cathode and stainless steel (SS) fiber as the anode with a compact $\mathrm{TiO}_{2^{-}}$ blocking layer of the cell [148]. They coated the solid-state perovskite sensitizer on the top of the anode, followed by a coating of the HTM (Spiro-OMeTAD), and finally twisting with transparent MWCNT sheets (Fig. 19). They obtained a maximum power conversion efficiency of $3.3 \%$ with excellent stability compared to any other 1D fiber-shaped photovoltaic devices [148]. However, it was quite challenging to obtain a continuous compact layer of $\mathrm{TiO}_{2}\left(\mathrm{c}-\mathrm{TiO}_{2}\right)$ and to deposit m$\mathrm{TiO}_{2}$ uniformly on the anode of the PSCs. Considering this problem, Lee et al. developed a novel dimpled compact layer of $\mathrm{TiO}_{2}\left(\mathrm{dc}-\mathrm{TiO}_{2}\right)$ and used silver nanowires $(\mathrm{Ag} \mathrm{NWs})$ as the top electrode for the fiber-shaped PSCs (Fig. 20), which exhibited a maximum PCE of 3.85\% [149]. The increased surface area of dc- $-\mathrm{TiO}_{2}$ allows for improved contact between the substrate and mesoscopic scaffold resulting in a reduction of the electrical resistance [149]. Although the relative ease of the solution-based deposition of transparent, conductive, and flexible Ag NWs offers advantages for large-scale manufacture, the solution-based deposition process may have deleterious effects on the perovskite film.

Later, $\mathrm{Hu}$ et al. integrated traditional perovskite solar cells into fiber format, utilizing Ti wire as working electrode and managed to improve the fill factor with a maximum PCE of $5.35 \%$ [150]. They found that the highly symmetrical fiberbased PSCs can harvest solar energy from 3D space/ regardless of the angle of the incident light, and the cell architecture produced consistent results [150]. A schematic
Fig. 20 (a) Schematic illustration of the structure of the fiber-shaped PSC: silver nanowires (Ag NWs) as the counter electrode and $\mathrm{Ti}$ wire as the working electrode, (b) SEM image of the fiber-shaped PSC device. (c) Magnified image — scale $500 \mathrm{~nm}$ [149]

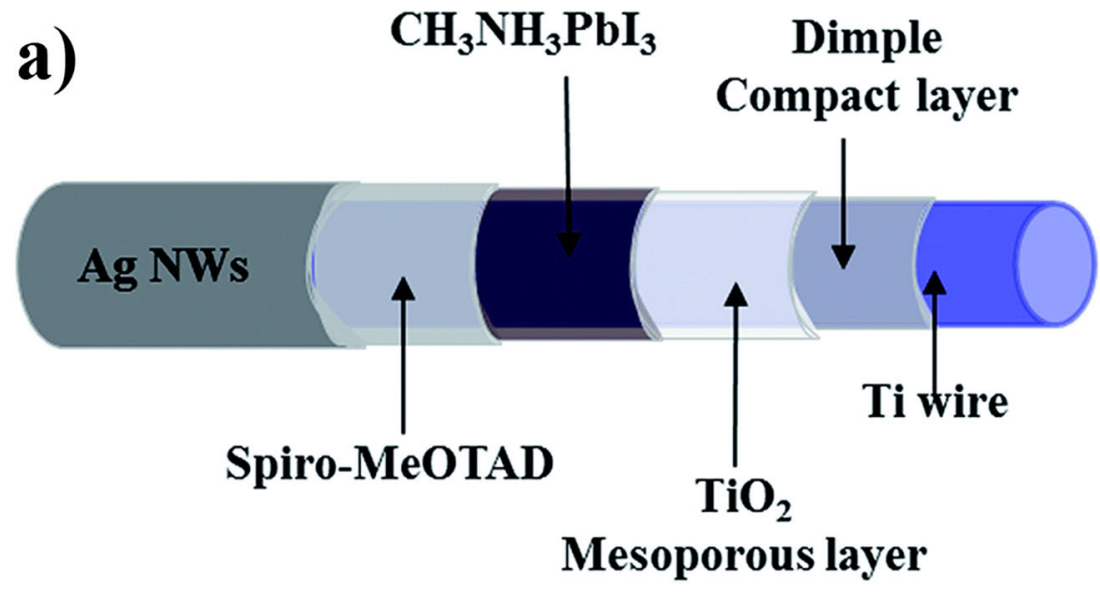

b)

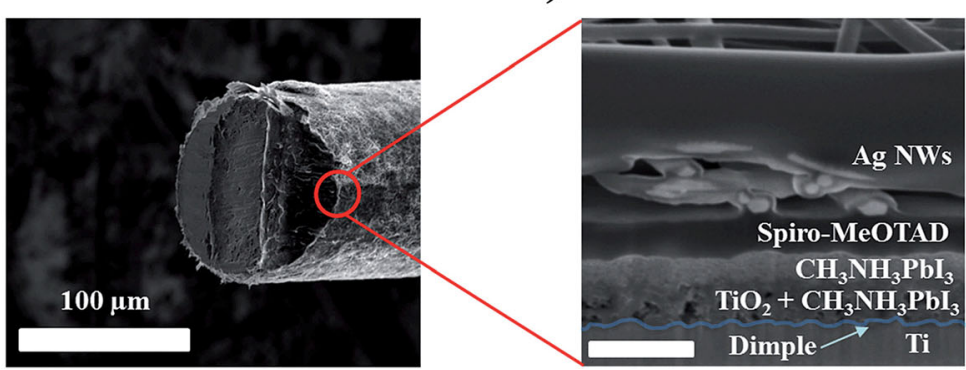


Fig. 21 Schematic of the fibershaped perovskite solar cell: (a) Structure. (b) SEM crosssectional image. (c) Image of typical FPSC [150]
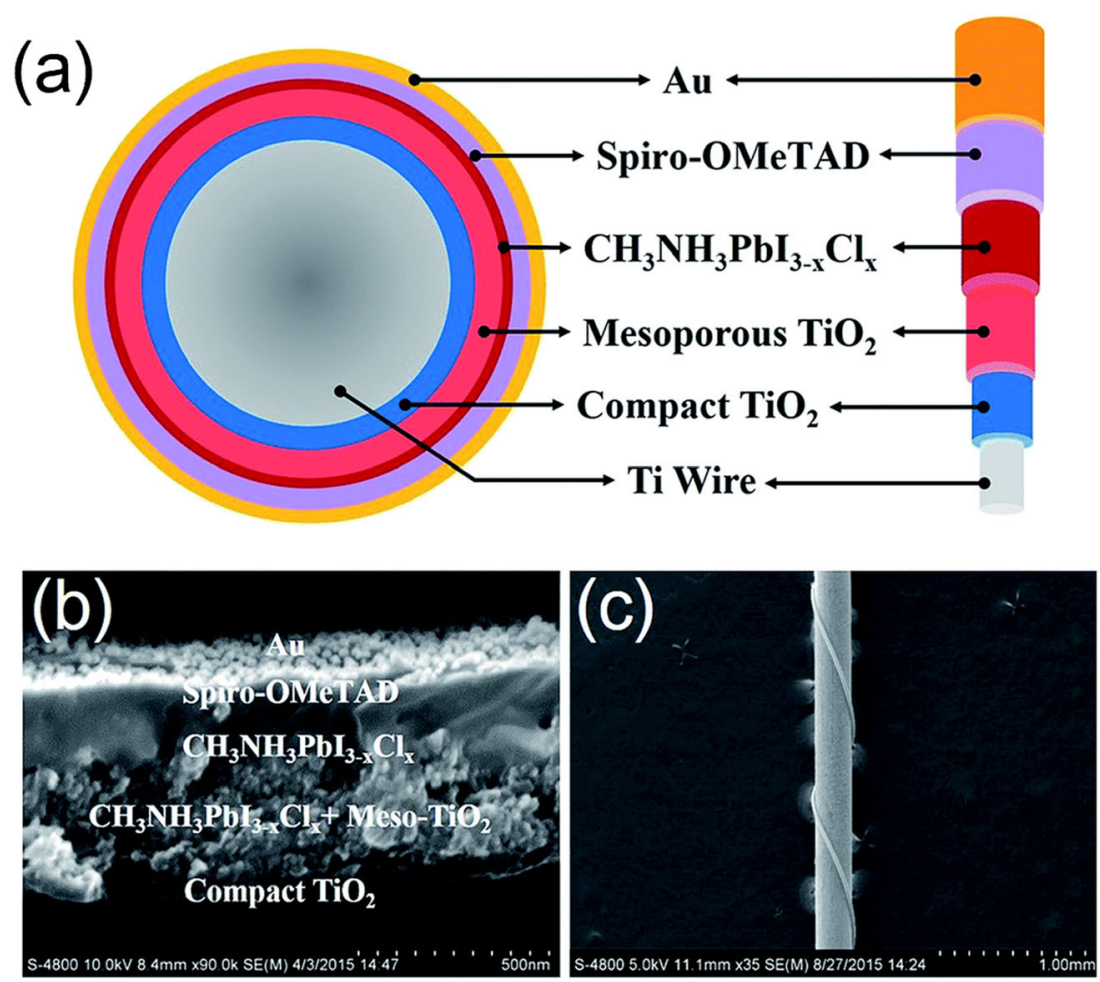

illustration of the novel fiber-shaped perovskite solar cell (FPSC) is shown in Fig. 21a; the flexible gold wire was used as the counter electrode and was twisted around the central fiber as shown in Fig. 21c.

$\mathrm{TiO}_{2}$ nanotubes have also garnered interest in the field of flexible PSCs due to their unique morphology. Wang et al. first demonstrated wire-shaped PSCs based on $\mathrm{TiO}_{2}$ nanotube/Ti wire with a perovskite layer deposited by successive dip coating [151]. The schematic illustration of the wirebased PSC and the stepwise fabrication process is shown in Fig. 22. Although this device only obtained a PCE of $1.16 \%$, its simple fabrication approach holds promise for the largescale cheap manufacture of portable, wearable, self-powered textile-based electronics.
Besides high efficiency and stability, PSCs need to withstand the stress produced during stretching and bending if they are going to be successfully commercialized; otherwise, such cells will break/fracture and will not retain operational PCEs beyond a short period of time. A metallic film/a perovskite layer deposited on an elastic substrate can be cracked/buckled during stretching [151]; to overcome this issue, Deng et al. developed an elastic perovskite solar cell utilizing a stretchable, interaligned/nanostructured, CNT-based conductive fiber and a spring-like modified $\mathrm{Ti}$ wire as the counter and working electrode, respectively [152]. A mixed halide perovskite layer was then deposited on the modified Ti wire with a dip-coating deposition process. The detailed fabrication process is illustrated in Fig. 23. They obtained PCEs ranging from
Fig. 22 Schematic representation of a wire-shaped perovskite solar cell: (a) the device structure and fabrication process; (b) energylevel diagram [151]
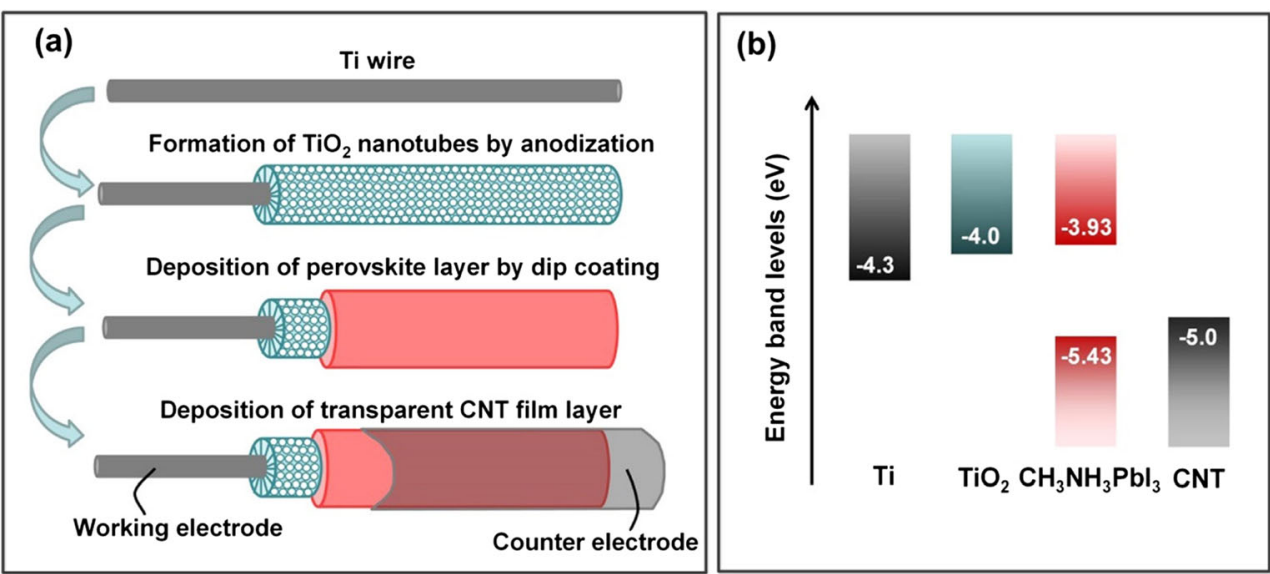
Fig. 23 Schematic illustration of the elastic PSC in fiber format. (a) Fabrication process, (b) energy level diagram, (c) device structure [141]

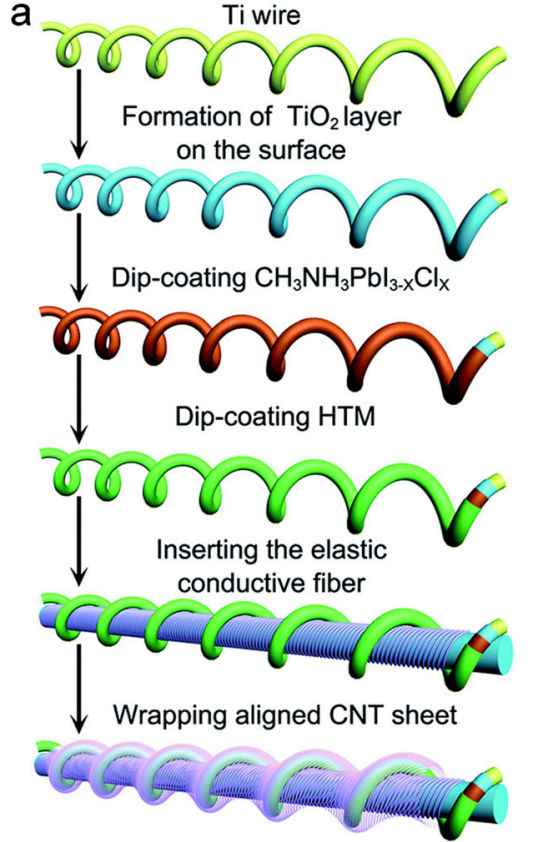

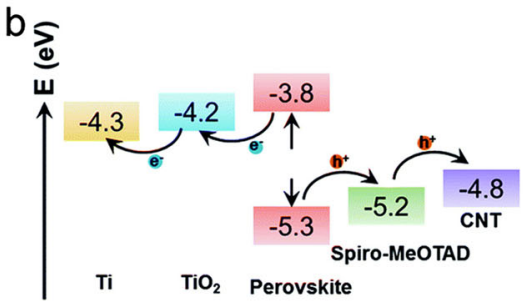

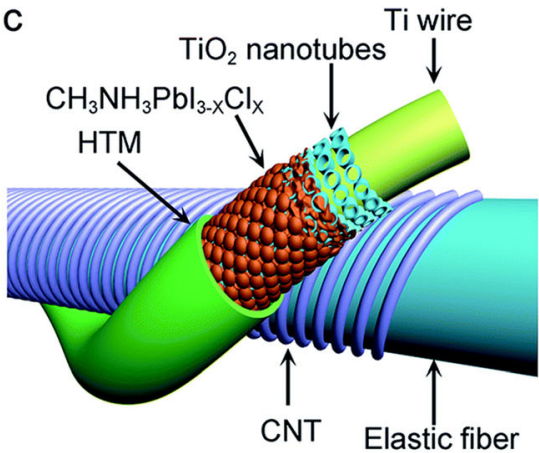

0.99 to $1.12 \%$ for ten devices, and these efficiencies were observed to only decrease by $\sim 10 \%$ after stretching 250 times at a strain of $30 \%$ and by $\sim 20 \%$ after $168 \mathrm{~h}$ even without sealing of the cells to protect the perovskite from the ambient conditions [152]. To the best of our knowledge, this one is the only elastic perovskite solar cell that has been developed up until now [152]. This flexible, elastic, and all solid-state structure exemplifies a potentially effective strategy for the development of next-generation photovoltaic devices.

\section{Conclusion}

Perovskite solar cells have seen remarkable development in the last few years after the discovery of the solid-state perovskite photosensitizer in 2012. The shift from traditional mesoscopic structures to planar structures, the transition from liquid sensitizers to all solid-state structures, and the simplicity and straightforward nature of new low-temperature fabrication methods will all undoubtedly aid in improving the PCE/ stability of PSCs and accelerate progress towards their eventual commercialization. Although perovskite solar cells have already obtained a record-certified PCE of $22.7 \%$, other factors also need to be considered when judging cell quality, for example - thermal and chemical stability, hysteresis, and toxicity of the cell components. Optimizing the chemical composition of the constituent materials and rationally engineering the device architecture are efficient routes towards increasing the light-harvesting/charge collection, enhancing the overall efficiency and stability of PSCs. Different organic and inorganic materials have been well-investigated, leading to rapid advancements in this emerging photovoltaic technology.
Moreover, the introduction of fiber/wire type flexible perovskite solar cells opens a new door towards their use in the next generation of wearable/portable electronics. The recent progress in novel material-based perovskite solar cells promises to lower manufacturing costs and produce more broadly applicable cells. The efforts to optimize the materials and architecture of PSCs, as well as the introduction of new functional materials, will lead to the development of flexible, inexpensive, and highly efficient perovskite solar cells with long life spans.

Open Access This article is distributed under the terms of the Creative Commons Attribution 4.0 International License (http:// creativecommons.org/licenses/by/4.0/), which permits unrestricted use, distribution, and reproduction in any medium, provided you give appropriate credit to the original author(s) and the source, provide a link to the Creative Commons license, and indicate if changes were made.

\section{References}

1. U.S. Energy Information Administration, What is U.S. electricity generation by energy source, https://www.eia.gov/tools/faqs/faq. php?id=427\&t=3, accessed: July, 2017

2. Q. Wang, Y. Xie, F. Soltani-Kordshuli, M. Eslamian, Renew. Sust. Energ. Rev. 56, 347 (2016)

3. J. Jaksik, H.J. Moore, T. Trad, O.I. Okoli, M.J. Uddin, Sol. Energy Mater. Sol. Cells 167, 121 (2017)

4. J. Mohtasham, Review article-renewable energies. Energy Procedia 74, 1289-1297 (2015)

5. M.A. Green, Third generation photovoltaics: ultra-high conversion efficiency at low cost. Prog. Photovolt. Res. Appl. 9, 123135 (2001)

6. K.D.G.I. Jayawardena, L.J. Rozanski, C.A. Mills, M.J. Beliatis, N.A. Nismy, S.R.P. Silva, 'Inorganics-in-organics': recent developments and outlook for $4 \mathrm{G}$ polymer solar cells. Nanoscale 5, 8411-8427 (2013) 
7. F. Giustino, H.J. Snaith, Toward lead-free perovskite solar cells. ACS Energy Lett. 1, 1233-1240 (2016)

8. A. Kojima, K. Teshima, Y. Shirai, T. Miyasaka, Organometal halide perovskites as visible-light sensitizers for photovoltaic cells. J. Am. Chem. Soc. 131, 6050-6051 (2009)

9. H.-S. Kim, C.-R. Lee, J.-H. Im, K.-B. Lee, T. Moehl, A. Marchioro, S.-J. Moon, R. Humphry-Baker, J.-H. Yum, J.E. Moser, M. Grätzel, N.-G. Park, Lead Iodide Perovskite Sensitized All-Solid-State Submicron Thin Film Mesoscopic Solar Cell with Efficiency Exceeding 9\%. Sci. Rep. 2, 591 (2012)

10. J. Seo, J.H. Noh, S.I. Seok, Rational strategies for efficient perovskite solar cells. Acc. Chem. Res. 49, 562-572 (2016)

11. G.E. Eperon, S.D. Stranks, C. Menelaou, M.B. Johnston, L.M. Herz, H.J. Snaith, Energy Environ. Sci. 7, 982 (2014)

12. J.H. Noh, S.H. Im, J.H. Heo, T.N. Mandal, S.I. Seok, Nano Lett. 13, 1764 (2013)

13. W.S. Yang, J.H. Noh, N.J. Jeon, Y.C. Kim, S. Ryu, J. Seo, S.I. Seok, High-performance photovoltaic perovskite layers fabricated through intramolecular exchange. Science 348, 1234-1237 (2015)

14. G. Xing, N. Mathews, S. Sun, S.S. Lim, Y.M. Lam, M. Grätzel, S. Mhaisalkar, T.C. Sum, Long-range balanced electron- and holetransport lengths in organic-inorganic $\mathrm{CH} 3 \mathrm{NH} 3 \mathrm{PbI} 3$. Science 342, 344-347 (2013)

15. S.D. Stranks, G.E. Eperon, G. Grancini, C. Menelaou, M.J.P. Alcocer, T. Leijtens, L.M. Herz, A. Petrozza, H.J. Snaith, Science 342, 341 (2013)

16. J.T.-W. Wang, J.M. Ball, E.M. Barea, A. Abate, J.A. AlexanderWebber, J. Huang, M. Saliba, I. Mora-Sero, J. Bisquert, H.J. Snaith, R.J. Nicholas, Low-temperature processed electron collection layers of graphene/Tio2nanocomposites in thin film perovskite solar cells. Nano Lett. 14, 724-730 (2014)

17. H.-S. Kim, S.H. Im, N.-G. Park, J. Phys. Chem. C 118, 5615 (2014)

18. Y. Shi, Y. Xing, Y. Li, Q. Dong, K. Wang, Y. Du, X. Bai, S. Wang, Z. Chen, T. Ma, CH3NH3PbI3 and CH3NH3PbI3-xClxin planar or mesoporous perovskite solar cells: comprehensive insight into the dependence of performance on architecture. J. Phys. Chem. C 119, 15868-15873 (2015)

19. R.K. Misra, S. Aharon, M. Layani, S. Magdassi, L. Etgar, J. Mater. Chem. A 4, 14423 (2016)

20. M. Liu, M.B. Johnston, H.J. Snaith, Efficient planar heterojunction perovskite solar cells by vapour deposition. Nature 501, 395-398 (2013)

21. G. Yang, H. Tao, P. Qin, W. Ke, G. Fang, Recent progress in electron transport layers for efficient perovskite solar cells. J. Mater. Chem. A 4, 3970-3990 (2016)

22. H. Zhou, Q. Chen, G. Li, S. Luo, T. Song, H.-S. Duan, Z. Hong, J. You, Y. Liu, Y. Yang, Interface engineering of highly efficient perovskite solar cells. Science 345, 542-546 (2014)

23. Z. Zhou, S. Pang, Z. Liu, H. Xu, G. Cui, Interface engineering for high-performance perovskite hybrid solar cells. J. Mater. Chem. A 3, 19205-19217 (2015)

24. G. Yang, C. Wang, H. Lei, X. Zheng, P. Qin, L. Xiong, X. Zhao, Y. Yan, G. Fang, Interface engineering in planar perovskite solar cells: energy level alignment, perovskite morphology control and high performance achievement. J. Mater. Chem. A 5, 1658-1666 (2017)

25. J.-H. Im, C.-R. Lee, J.-W. Lee, S.-W. Park, N.-G. Park, 6.5\% efficient perovskite quantum-dot-sensitized solar cell. Nanoscale 3, 4088-4093 (2011)

26. M.M. Lee, J. Teuscher, T. Miyasaka, T.N. Murakami, H.J. Snaith, Science 338, 643 (2012)

27. J.M. Ball, M.M. Lee, A. Hey, H.J. Snaith, Low-temperature processed meso-superstructured to thin-film perovskite solar cells. Energy Environ. Sci. 6, 1739 (2013)
28. J. Burschka, N. Pellet, S.-J. Moon, R. Humphry-Baker, P. Gao, M.K. Nazeeruddin, M. Grätzel, Nature 499, 316 (2013)

29. N.J. Jeon, H.G. Lee, Y.C. Kim, J. Seo, J.H. Noh, J. Lee, S.I. Seok, o-Methoxy substituents in Spiro-OMeTAD for efficient inorganic-organic hybrid perovskite solar cells. J. Am. Chem. Soc. 136, 7837-7840 (2014)

30. J.P.C. Baena, L. Steier, W. Tress, M. Saliba, S. Neutzner, T. Matsui, F. Giordano, T.J. Jacobsson, A.R.S. Kandada, S.M. Zakeeruddin, A. Petrozza, A. Abate, M.K. Nazeeruddin, M. Grätzel, A. Hagfeldt, Energy Environ. Sci. 8, 2928 (2015)

31. E.H. Anaraki, A. Kermanpur, L. Steier, K. Domanski, T. Matsui, W. Tress, M. Saliba, A. Abate, M. Grätzel, A. Hagfeldt, J.-P. Correa-Baena, Highly efficient and stable planar perovskite solar cells by solution-processed tin oxide. Energy Environ. Sci. 9, 3128-3134 (2016)

32. M. Saliba, T. Matsui, K. Domanski, J.-Y. Seo, A. Ummadisingu, S.M. Zakeeruddin, J.-P. Correa-Baena, W.R. Tress, A. Abate, A. Hagfeldt, M. Grätzel, Incorporation of rubidium cations into perovskite solar cells improves photovoltaic performance. Science. 354(6309), 206-209 (2016). https://doi.org/10.1126/science. aah5557

33. NREL, Best Research-Cell Efficiencies, http://www.nrel.gov, accessed: May 2018

34. M. Habibi, F. Zabihi, M.R. Ahmadian-Yazdi, M. Eslamian, Progress in emerging solution-processed thin film solar cells Part II: perovskite solar cells. Renew. Sust. Energ. Rev. 62, 1012-1031 (2016)

35. N.-G. Park, Perovskite solar cells: an emerging photovoltaic technology. Mater. Today 18, 65-72 (2015)

36. C. Li, X. Lu, W. Ding, L. Feng, Y. Gao, Z. Guo, Acta Crystallogr. B 64, 702 (2008)

37. V.M. Goldschmidt, Die Gesetze der Krystallochemie. Naturwissenschaften 14, 477-485 (1926)

38. M.A. Green, A. Ho-Baillie, H.J. Snaith, Nat. Photonics 8, 506 (2014)

39. N. Marinova, S. Valero, J.L. Delgado, J. Colloid Interface Sci. 488, 373 (2017)

40. M.I. Asghar, J. Zhang, H. Wang, P.D. Lund, Renew. Sust. Energ. Rev. 77, 131 (2017)

41. J. Chen, N.-G. Park, Inorganic Hole Transporting Materials for Stable and High Efficiency Perovskite Solar Cells. J. Phys. Chem. C 122(25), 14039-14063 (2018). https://doi.org/10.1021/ acs.jpcc. 8 b01177

42. Z. Song, S.C. Watthage, A.B. Phillips, M.J. Heben, Pathways toward high-performance perovskite solar cells: review of recent advances in organo-metal halide perovskites for photovoltaic applications. J. Photonics Energy 6, 022001 (2016)

43. H.-S. Kim, N.-G. Park, Parameters Affecting I-V Hysteresis of CH3NH3PbI3 Perovskite Solar Cells: Effects of Perovskite Crystal Size and Mesoporous $\mathrm{TiO}_{2}$ Laye. J. Phys. Chem. Lett. 5(17), 2927-2934 (2014). https://doi.org/10.1021/jz501392m

44. J. Wei, Y. Zhao, H. Li, G. Li, J. Pan, D. Xu, Q. Zhao, D. Yu, Hysteresis Analysis Based on the Ferroelectric Effect in Hybrid Perovskite Solar Cells. J. Phys. Chem. Lett. 5(21), 3937-3945 (2014). https://doi.org/10.1021/jz502111u

45. H.-S. Kim, I.-H. Jang, N. Ahn, M. Choi, A. Guerrero, J. Bisquert, N.-G. Park, Control of I-V Hysteresis in $\mathrm{CH} 3 \mathrm{NH} 3 \mathrm{PbI} 3$ Perovskite Solar Cell. J. Phys. Chem. Lett. 6(22), 4633-4639 (2015). https://doi.org/10.1021/acs.jpclett.5b02273

46. B. Chen, M. Yang, S. Priya, K. Zhu, Origin of J-V Hysteresis in Perovskite Solar Cells. J. Phys. Chem. Lett. 7(5), 905-917 (2016). https://doi.org/10.1021/acs.jpclett.6b00215

47. Z. Shi, A.H. Jayatissa, Perovskites-Based Solar Cells: A Review of Recent Progress, Materials and Processing Methods. Materials. 11(5), 729 (2018). https://doi.org/10.3390/ma11050729 
48. L. Meng, J. You, T.-F. Guo, Y. Yang, Recent Advances in the Inverted Planar Structure of Perovskite Solar Cells. Acc. Chem. Res. 49(1), 155-165 (2016). https://doi.org/10.1021/acs.accounts. 5 b00404

49. J.-Y. Jeng, Y.-F. Chiang, M.-H. Lee, S.-R. Peng, T.-F. Guo, P. Chen, T.-C. Wen, Adv. Mater. 25, 3727 (2013)

50. L. Hu, K. Sun, M. Wang, W. Chen, B. Yang, J. Fu, Z. Xiong, X. Li, X. Tang, Z. Zang, S. Zhang, L. Sun, M. Li, Inverted Planar Perovskite Solar Cells with a High Fill Factor and Negligible Hysteresis by the Dual Effect of NaCl-Doped PEDOT:PSS. ACS Appl. Mater. Interfaces. 9(50), 43902-43909 (2017). https://doi.org/10.1021/acsami.7b14592

51. L. Etgar, P. Gao, Z. Xue, Q. Peng, A.K. Chandiran, B. Liu, M.K. Nazeeruddin, M. Grätzel, Mesoscopic CH3NH3PbI3/ Tio2heterojunction solar cells. J. Am. Chem. Soc. 134, 1739617399 (2012)

52. L. Huang, J. Xu, X. Sun, Y. Du, H. Cai, J. Ni, J. Li, Z. Hu, J. Zhang, ACS Appl. Mater. Interfaces 8, 9811 (2016)

53. Q. Hu, J. Wu, C. Jiang, T. Liu, X. Que, R. Zhu, Q. Gong, Engineering of electron-selective contact for perovskite solar cells with efficiency exceeding 15\%. ACS Nano 8, 10161-10167 (2014)

54. W. Ke, G. Fang, J. Wan, H. Tao, Q. Liu, L. Xiong, P. Qin, J. Wang, H. Lei, G. Yang, M. Qin, X. Zhao, Y. Yan, Nat. Commun. 6, ncomms 7700 (2015)

55. D. Liu, J. Yang, T.L. Kelly, Compact layer free perovskite solar cells with $13.5 \%$ efficiency. J. Am. Chem. Soc. 136, 17116-17122 (2014)

56. Z. Chen, Q. Dong, Y. Liu, C. Bao, Y. Fang, Y. Lin, S. Tang, Q. Wang, X. Xiao, Y. Bai, Y. Deng, J. Huang, Nat. Commun. 8, 1890 (2017)

57. D. Prochowicz, P. Yadav, M. Saliba, M. Saski, S.M. Zakeeruddin, J. Lewiński, M. Grätzel, Sustain. Energy Fuels 1, 689 (2017)

58. D.M. Jang, K. Park, D.H. Kim, J. Park, F. Shojaei, H.S. Kang, J.-P. Ahn, J.W. Lee, J.K. Song, Nano Lett. 15, 5191 (2015)

59. W.-J. Yin, J.-H. Yang, J. Kang, Y. Yan, S.-H. Wei, Halide perovskite materials for solar cells: a theoretical review. J. Mater. Chem. A 3, 8926-8942 (2015)

60. L. Huang, Z. Hu, J. Xu, X. Sun, Y. Du, J. Ni, H. Cai, J. Li, J. Zhang, Efficient planar perovskite solar cells without a high temperature processed titanium dioxide electron transport layer. Sol. Energy Mater. Sol. Cells 149, 1-8 (2016)

61. J.-W. Lee, D.-J. Seol, A.-N. Cho, N.-G. Park, High-efficiency perovskite solar cells based on the black polymorph of HC(NH2)2PbI3. Adv. Mater. 26, 4991-4998 (2014)

62. Q. Zhu, X. Bao, J. Yu, D. Zhu, M. Qiu, R. Yang, L. Dong, Compact layer free perovskite solar cells with a high-mobility hole-transporting layer. ACS Appl. Mater. Interfaces 8, 26522657 (2016)

63. S. Aharon, S. Gamliel, B.E. Cohen, L. Etgar, Depletion region effect of highly efficient hole conductor free CH3NH3PbI3perovskite solar cells. Phys. Chem. Chem. Phys. 16, 10512-10518 (2014)

64. A. Mei, X. Li, L. Liu, Z. Ku, T. Liu, Y. Rong, M. Xu, M. Hu, J. Chen, Y. Yang, M. Grätzel, H. Han, A hole-conductor-free, fully printable mesoscopic perovskite solar cell with high stability. Science 345, 295-298 (2014)

65. N.J. Jeon, J.H. Noh, W.S. Yang, Y.C. Kim, S. Ryu, J. Seo, S.I. Seok, Compositional engineering of perovskite materials for highperformance solar cells. Nature 517, 476-480 (2015)

66. N. Pellet, P. Gao, G. Gregori, T.-Y. Yang, M.K. Nazeeruddin, J. Maier, M. Grätzel, Mixed-organic-cation perovskite photovoltaics for enhanced solar-light harvesting. Angew. Chem. Int. Ed. 53, 3151-3157 (2014)
67. J.-P. Correa-Baena, A. Abate, M. Saliba, W. Tress, T.J. Jacobsson, M. Grätzel, A. Hagfeldt, The rapid evolution of highly efficient perovskite solar cells. Energy Environ. Sci. 10, 710-727 (2017)

68. J.-W. Lee, D.-H. Kim, H.-S. Kim, S.-W. Seo, S.M. Cho, N.-G. Park, Adv. Energy Mater. 5, n/a (2015)

69. M. Saliba, T. Matsui, J.-Y. Seo, K. Domanski, J.-P. Correa-Baena, M. Khaja Nazeeruddin, S.M. Zakeeruddin, W. Tress, A. Abate, A. Hagfeldt, M. Grätzel, Cesium-containing triple cation perovskite solar cells: improved stability, reproducibility and high efficiency. Energy Environ. Sci. 9, 1989-1997 (2016)

70. C. Liu, J. Fan, H. Li, C. Zhang, Y. Mai, Sci. Rep. 6, srep35705 (2016)

71. Y. Liu, Z. Yang, D. Cui, X. Ren, J. Sun, X. Liu, J. Zhang, Q. Wei, H. Fan, F. Yu, X. Zhang, C. Zhao, S.(.F.). Liu, Two-inch-sized perovskite $\mathrm{CH} 3 \mathrm{NH} 3 \mathrm{PbX} 3(\mathrm{X}=\mathrm{Cl}, \mathrm{Br}, \mathrm{I})$ crystals: growth and characterization. Adv. Mater. 27, 5176-5183 (2015)

72. E. Edri, S. Kirmayer, M. Kulbak, G. Hodes, D. Cahen, Chloride inclusion and hole transport material doping to improve methyl ammonium lead bromide perovskite-based high open-circuit voltage solar cells. J. Phys. Chem. Lett. 5, 429-433 (2014)

73. B. Suarez, V. Gonzalez-Pedro, T.S. Ripolles, R.S. Sanchez, L. Otero, I. Mora-Sero, J. Phys. Chem. Lett. 5, 1628 (2014)

74. H. Choi, J. Jeong, H.-B. Kim, S. Kim, B. Walker, G.-H. Kim, J.Y. Kim, Nano Energy 7, 80 (2014)

75. T.J. Jacobsson, J.-P. Correa-Baena, M. Pazoki, M. Saliba, K. Schenk, M. Grätzel, A. Hagfeldt, Exploration of the compositional space for mixed lead halogen perovskites for high efficiency solar cells. Energy Environ. Sci. 9, 1706-1724 (2016)

76. N.K. Noel, S.D. Stranks, A. Abate, C. Wehrenfennig, S. Guarnera, A.-A. Haghighirad, A. Sadhanala, G.E. Eperon, S.K. Pathak, M.B. Johnston, A. Petrozza, L.M. Herz, H.J. Snaith, Lead-free organicinorganic tin halide perovskites for photovoltaic applications. Energy Environ. Sci. 7, 3061-3068 (2014)

77. W.-J. Yin, Y. Yan, S.-H. Wei, Anomalous alloy properties in mixed halide perovskites. J. Phys. Chem. Lett. 5, 3625-3631 (2014)

78. T. Krishnamoorthy, H. Ding, C. Yan, W.L. Leong, T. Baikie, Z. Zhang, M. Sherburne, S. Li, M. Asta, N. Mathews, S.G. Mhaisalkar, Lead-free germanium iodide perovskite materials for photovoltaic applications. J. Mater. Chem. A 3, 23829-23832 (2015)

79. X.-P. Cui, K.-J. Jiang, J.-H. Huang, Q.-Q. Zhang, M.-J. Su, L.-M. Yang, Y.-L. Song, X.-Q. Zhou, Cupric bromide hybrid perovskite heterojunction solar cells. Synth. Met. 209, 247-250 (2015)

80. P.C. Harikesh, H.K. Mulmudi, B. Ghosh, T.W. Goh, Y.T. Teng, K. Thirumal, M. Lockrey, K. Weber, T.M. Koh, S. Li, S. Mhaisalkar, $\mathrm{N}$. Mathews, $\mathrm{Rb}$ as an alternative cation for templating inorganic lead-free perovskites for solution processed photovoltaics. Chem. Mater. 28, 7496-7504 (2016)

81. B.-W. Park, B. Philippe, X. Zhang, H. Rensmo, G. Boschloo, E.M.J. Johansson, Bismuth based hybrid Perovskites A3Bi2I9(A: methylammonium or cesium) for solar cell application. Adv. Mater. 27, 6806-6813 (2015)

82. T.J. Jacobsson, M. Pazoki, A. Hagfeldt, T. Edvinsson, Goldschmidt's rules and strontium replacement in lead halogen perovskite solar cells: theory and preliminary experiments on CH3NH3SrI3. J. Phys. Chem. C 119, 25673-25683 (2015)

83. L. Li, F. Zhang, Y. Hao, Q. Sun, Z. Li, H. Wang, Y. Cui, F. Zhu, High efficiency planar $\mathrm{Sn}-\mathrm{Pb}$ binary perovskite solar cells: controlled growth of large grains via a one-step solution fabrication process. J. Mater. Chem. C 5, 2360-2367 (2017)

84. Y. Li, W. Sun, W. Yan, S. Ye, H. Rao, H. Peng, Z. Zhao, Z. Bian, Z. Liu, H. Zhou, C. Huang, Adv. Energy Mater. 6, n/a (2016)

85. W. Liao, D. Zhao, Y. Yu, N. Shrestha, K. Ghimire, C.R. Grice, C. Wang, Y. Xiao, A.J. Cimaroli, R.J. Ellingson, N.J. Podraza, K. Zhu, R.-G. Xiong, Y. Yan, J. Am. Chem. Soc. 138, 12360 (2016) 
86. C.-Y. Chang, C.-Y. Chu, Y.-C. Huang, C.-W. Huang, S.-Y. Chang, C.-A. Chen, C.-Y. Chao, W.-F. Su, ACS Appl. Mater. Interfaces 7, $4955(2015)$

87. J. Qian, B. Xu, W. Tian, A comprehensive theoretical study of halide perovskites ABX 3. Org. Electron. 37, 61-73 (2016)

88. B. Conings, L. Baeten, T. Jacobs, R. Dera, J. D’Haen, J. Manca, H.-G. Boyen, APL Mater. 2, 081505 (2014)

89. I. Kopacic, B. Friesenbichler, S.F. Hoefler, B. Kunert, H. Plank, T. Rath, G. Trimmel, Enhanced performance of germanium halide perovskite solar cells through compositional engineering. ACS Appl. Energy Mater. 1, 343-347 (2018)

90. X. Shai, L. Zuo, P. Sun, P. Liao, W. Huang, E.-P. Yao, H. Li, S. Liu, Y. Shen, Y. Yang, M. Wang, Efficient planar perovskite solar cells using halide $\mathrm{Sr}$-substituted $\mathrm{Pb}$ perovskite. Nano Energy 36, 213-222 (2017)

91. J.-H. Im, H.-S. Kim, N.-G. Park, Morphology-photovoltaic property correlation in perovskite solar cells: One-step versus two-step deposition of CH3NH3PbI3. APL Mater. 2, 081510 (2014)

92. S. Razza, F. Di Giacomo, F. Matteocci, L. Cinà, A.L. Palma, S. Casaluci, P. Cameron, A. D’Epifanio, S. Licoccia, A. Reale, T.M. Brown, A. Di Carlo, Perovskite solar cells and large area modules $(100 \mathrm{~cm} 2$ ) based on an air flow-assisted PbI 2 blade coating deposition process. J. Power Sources 277, 286-291 (2015)

93. M. Adnan, J.K. Lee, All sequential dip-coating processed perovskite layers from an aqueous lead precursor for high efficiency perovskite solar cells. Sci. Rep. 8, 2168 (2018)

94. J.-E. Kim, Y.-S. Jung, Y.-J. Heo, K. Hwang, T. Qin, D.-Y. Kim, D. Vak, Slot die coated planar perovskite solar cells via blowing and heating assisted one step deposition. Sol. Energy Mater. Sol. Cells 179, 80-86 (2018)

95. M. Habibi, M.-R. Ahmadian-Yazdi, M. Eslamian, J. Photonics Energy 7, 022003 (2017)

96. F. Mathies, H. Eggers, B.S. Richards, G. Hernandez-Sosa, U. Lemmer, U.W. Paetzold, Inkjet-Printed Triple Cation Perovskite Solar Cells. ACS Appl. Energy Mater. 1(5), 1834-1839 (2018). https://doi.org/10.1021/acsaem.8b00222

97. L.K. Ono, M.R. Leyden, S. Wang, Y. Qi, Organometal halide perovskite thin films and solar cells by vapor deposition. J. Mater. Chem. A 4, 6693-6713 (2016)

98. L. Tzounis, T. Stergiopoulos, A. Zachariadis, C. Gravalidis, A. Laskarakis, S. Logothetidis, Perovskite solar cells from small scale spin coating process towards roll-to-roll printing: optical and morphological studies. Mater. Today Proc. 4, 5082-5089 (2017)

99. Y. Deng, E. Peng, Y. Shao, Z. Xiao, Q. Dong, J. Huang, Scalable fabrication of efficient organolead trihalide perovskite solar cells with doctor-bladed active layers. Energy Environ. Sci. 8, 1544 1550 (2015)

100. J. Song, E. Zheng, J. Bian, X.-F. Wang, W. Tian, Y. Sanehira, T. Miyasaka, J. Mater. Chem. A 3, 10837 (2015)

101. G. Cotella, J. Baker, D. Worsley, F. De Rossi, C. Pleydell-Pearce, M. Carnie, T. Watson, Sol. Energy Mater. Sol. Cells 159, 362 (2017)

102. W. Ke, G. Fang, Q. Liu, L. Xiong, P. Qin, H. Tao, J. Wang, H. Lei, B. Li, J. Wan, G. Yang, Y. Yan, Low-temperature solution-processed tin oxide as an alternative electron transporting layer for efficient perovskite solar cells. J. Am. Chem. Soc. 137, 6730 $6733(2015)$

103. T. Qin, W. Huang, J.-E. Kim, D. Vak, C. Forsyth, C.R. McNeill, Y.-B. Cheng, Amorphous hole-transporting layer in slot-die coated perovskite solar cells. Nano Energy 31, 210-217 (2017)

104. M. Qin, J. Ma, W. Ke, P. Qin, H. Lei, H. Tao, X. Zheng, L. Xiong, Q. Liu, Z. Chen, J. Lu, G. Yang, G. Fang, Perovskite solar cells based on low-temperature processed indium oxide electron selective layers. ACS Appl. Mater. Interfaces 8, 8460-8466 (2016)

105. K. Wang, Y. Shi, Q. Dong, Y. Li, S. Wang, X. Yu, M. Wu, T. Ma, Low-temperature and solution-processed amorphous woxas electron-selective layer for perovskite solar cells. J. Phys. Chem. Lett. 6, 755-759 (2015)

106. W.-Q. Wu, D. Chen, R.A. Caruso, Y.-B. Cheng, Recent progress in hybrid perovskite solar cells based on n-type materials. J. Mater. Chem. A 5, 10092-10109 (2017)

107. X. Wang, L.-L. Deng, L.-Y. Wang, S.-M. Dai, Z. Xing, X.-X. Zhan, X.-Z. Lu, S.-Y. Xie, R.-B. Huang, L.-S. Zheng, Cerium oxide standing out as an electron transport layer for efficient and stable perovskite solar cells processed at low temperature. J. Mater. Chem. A 5, 1706-1712 (2017)

108. A. Yella, L.-P. Heiniger, P. Gao, M.K. Nazeeruddin, M. Grätzel, Nanocrystalline rutile electron extraction layer enables lowtemperature solution processed perovskite photovoltaics with 13.7\% efficiency. Nano Lett. 14, 2591-2596 (2014)

109. C. Tao, S. Neutzner, L. Colella, S. Marras, A.R.S. Kandada, M. Gandini, M.D. Bastiani, G. Pace, L. Manna, M. Caironi, C. Bertarelli, A. Petrozza, $17.6 \%$ stabilized efficiency in lowtemperature processed planar perovskite solar cells. Energy Environ. Sci. 8, 2365-2370 (2015)

110. W. Tress, N. Marinova, O. Inganäs, M.K. Nazeeruddin, S.M. Zakeeruddin, M. Grätzel, The role of the hole-transport layer in perovskite solar cells - reducing recombination and increasing absorption. 2014 IEEE 40th Photovolt. Spec. Conf. PVSC., 1563-1566 (2014). https://doi.org/10.1109/PVSC.2014.6925216

111. T. Leijtens, G.E. Eperon, S. Pathak, A. Abate, M.M. Lee, H.J. Snaith, Nat. Commun. 4, ncomms3885 (2013)

112. W. Li, W. Zhang, S.V. Reenen, R.J. Sutton, J. Fan, A.A. Haghighirad, M.B. Johnston, L. Wang, H.J. Snaith, Enhanced UV-light stability of planar heterojunction perovskite solar cells with caesium bromide interface modification. Energy Environ. Sci. 9, 490-498 (2016)

113. L. Jiang, W. Chen, J. Zheng, L. Zhu, L. Mo, Z. Li, L. Hu, T. Hayat, A. Alsaedi, C. Zhang, S. Dai, Enhancing the Photovoltaic Performance of Perovskite Solar Cells with a Down-Conversion Eu-Complex. ACS Appl. Mater. Interfaces. 9(32), 26958-26964 (2017). https://doi.org/10.1021/acsami.7b10101

114. S. Gubbala, V. Chakrapani, V. Kumar, M.K. Sunkara, Adv. Funct. Mater. 18, 2411 (2008)

115. Q. Zhang, C.S. Dandeneau, X. Zhou, G. Cao, Adv. Mater. 21, 4087 (2009)

116. D.-Y. Son, J.-H. Im, H.-S. Kim, N.-G. Park, J. Phys. Chem. C 118, 16567 (2014)

117. D. Liu, T.L. Kelly, Nat. Photonics 8, 133 (2014)

118. X. Dong, H. Hu, B. Lin, J. Ding, N. Yuan, Chem. Commun. 50, 14405 (2014)

119. Y. Li, J. Zhu, Y. Huang, F. Liu, M. Lv, S. Chen, L. Hu, J. Tang, J. Yao, S. Dai, Mesoporous SnO2nanoparticle films as electrontransporting material in perovskite solar cells. RSC Adv. 5, 28424-28429 (2015)

120. S. Sun, T. Salim, N. Mathews, M. Duchamp, C. Boothroyd, G. Xing, T. Chien Sum, Y. Ming Lam, The origin of high efficiency in low-temperature solution-processable bilayer organometal halide hybrid solar cells. Energy Environ. Sci. 7, 399-407 (2014)

121. Q. Wang, Y. Shao, Q. Dong, Z. Xiao, Y. Yuan, J. Huang, Energy Environ. Sci. 7, 2359 (2014)

122. O. Malinkiewicz, A. Yella, Y.H. Lee, G.M. Espallargas, M. Graetzel, M.K. Nazeeruddin, H.J. Bolink, Perovskite solar cells employing organic charge-transport layers. Nat. Photonics 8, 128132 (2014)

123. Z. Yu, L. Sun, Adv. Energy Mater. 5, n/a (2015)

124. H. Xi, S. Tang, X. Ma, J. Chang, D. Chen, Z. Lin, P. Zhong, H. Wang, C. Zhang, Performance enhancement of planar heterojunction perovskite solar cells through tuning the doping properties of hole-transporting materials. ACS Omega 2, 326336 (2017) 
125. Z.H. Bakr, Q. Wali, A. Fakharuddin, L. Schmidt-Mende, T.M. Brown, R. Jose, Advances in hole transport materials engineering for stable and efficient perovskite solar cells. Nano Energy 34, 271-305 (2017)

126. J.H. Heo, S.H. Im, J.H. Noh, T.N. Mandal, C.-S. Lim, J.A. Chang, Y.H. Lee, H. Kim, A. Sarkar, M.K. Nazeeruddin, M. Grätzel, S.I. Seok, Efficient inorganic-organic hybrid heterojunction solar cells containing perovskite compound and polymeric hole conductors. Nat. Photonics 7, 486-491 (2013)

127. D. Bi, L. Yang, G. Boschloo, A. Hagfeldt, E.M.J. Johansson, Effect of Different Hole Transport Materials on Recombination in $\mathrm{CH} 3 \mathrm{NH} 3 \mathrm{PbI} 3$ Perovskite-Sensitized Mesoscopic Solar Cells. J. Phys. Chem. Lett. 4(9), 1532-1536 (2013). https://doi.org/10. 1021/jz400638x

128. H.A. Abbas, R. Kottokkaran, B. Ganapathy, M. Samiee, L. Zhang, A. Kitahara, M. Noack, V.L. Dalal, High efficiency sequentially vapor grown $n-i-p$ CH3NH3PbI3perovskite solar cells with undoped P3HT as p-type heterojunction layer. APL Mater. 3, 016105 (2015)

129. B. Conings, L. Baeten, C. De Dobbelaere, J. D'Haen, J. Manca, H.-G. Boyen, Adv. Mater. 26, 2041 (2014)

130. Y. Xiao, G. Han, Y. Chang, H. Zhou, M. Li, Y. Li, An all-solidstate perovskite-sensitized solar cell based on the dual function polyaniline as the sensitizer and p-type hole-transporting material. J. Power Sources 267, 1-8 (2014)

131. L. Calió, S. Kazim, M. Grätzel, S. Ahmad, Hole-transport materials for perovskite solar cells. Angew. Chem. Int. Ed. 55, 14522 14545 (2016)

132. H. Wang, Z. Yu, X. Jiang, J. Li, B. Cai, X. Yang, L. Sun, Efficient and stable inverted planar perovskite solar cells employing cui as hole-transporting layer prepared by solid-gas transformation. Energy Technol 5, 1836-1843 (2017)

133. S. Weber, T. Rath, J. Mangalam, B. Kunert, A.M. Coclite, M. Bauch, T. Dimopoulos, G. Trimmel, J. Mater. Sci. Mater. Electron. 29, 1847 (2018)

134. N. Wijeyasinghe, A. Regoutz, F. Eisner, T. Du, L. Tsetseris, Y.-H. Lin, H. Faber, P. Pattanasattayavong, J. Li, F. Yan, M.A. McLachlan, D.J. Payne, M. Heeney, T.D. Anthopoulos, Adv. Funct. Mater. 27, 1701818 (2017)

135. J.A. Christians, R.C.M. Fung, P.V. Kamat, An inorganic hole conductor for organo-lead halide perovskite solar cells. Improved hole conductivity with copper iodide. J. Am. Chem. Soc. 136, 758-764 (2014)

136. P. Qin, S. Tanaka, S. Ito, N. Tetreault, K. Manabe, H. Nishino, M.K. Nazeeruddin, M. Grätzel, Nat. Commun. 5, ncomms4834 (2014)

137. K.-C. Wang, P.-S. Shen, M.-H. Li, S. Chen, M.-W. Lin, P. Chen, T.-F. Guo, Low-temperature sputtered nickel oxide compact thin film as effective electron blocking layer for mesoscopic $\mathrm{NiO} /$ CH3NH3PbI3perovskite heterojunction solar cells. ACS Appl. Mater. Interfaces 6, 11851-11858 (2014)

138. R.H. Baughman, A.A. Zakhidov, W.A. de Heer, Science 297, 787 (2002)

139. S.N. Habisreutinger, R.J. Nicholas, H.J. Snaith, Adv. Energy Mater. 7, n/a (2017)

140. H. Chen, X. Pan, W. Liu, M. Cai, D. Kou, Z. Huo, X. Fang, S. Dai, Efficient panchromatic inorganic-organic heterojunction solar cells with consecutive charge transport tunnels in hole transport material. Chem. Commun. 49, 7277-7279 (2013)

141. S.N. Habisreutinger, T. Leijtens, G.E. Eperon, S.D. Stranks, R.J. Nicholas, H.J. Snaith, Carbon nanotube/polymer composites as a highly stable hole collection layer in perovskite solar cells. Nano Lett. 14, 5561-5568 (2014)

142. K. Aitola, K. Sveinbjörnsson, J.-P. Correa-Baena, A. Kaskela, A. Abate, Y. Tian, E.M.J. Johansson, M. Grätzel, E.I. Kauppinen, A. Hagfeldt, G. Boschloo, Carbon nanotube-based hybrid holetransporting material and selective contact for high efficiency perovskite solar cells. Energy Environ. Sci. 9, 461-466 (2016)

143. C.S. Ponseca, T.J. Savenije, M. Abdellah, K. Zheng, A. Yartsev, T. Pascher, T. Harlang, P. Chabera, T. Pullerits, A. Stepanov, J.-P. Wolf, V. Sundström, J. Am. Chem. Soc. 136, 5189 (2014)

144. M. Peng, D. Zou, Flexible fiber/wire-shaped solar cells in progress: properties, materials, and designs. J. Mater. Chem. A 3, 20435-20458 (2015)

145. M. Ye, X. Hong, F. Zhang, X. Liu, J. Mater. Chem. A 4, 6755 (2016)

146. L. Qiu, J. Deng, X. Lu, Z. Yang, H. Peng, Integrating perovskite solar cells into a flexible fiber. Angew. Chem. Int. Ed. 53, 1042510428 (2014)

147. M. Lee, Y. Ko, Y. Jun, J. Mater. Chem. A 3, 19310 (2015)

148. H. Hu, K. Yan, M. Peng, X. Yu, S. Chen, B. Chen, B. Dong, X. Gao, D. Zou, Fiber-shaped perovskite solar cells with 5.3\% efficiency. J. Mater. Chem. A 4, 3901-3906 (2016)

149. X. Wang, S.A. Kulkarni, Z. Li, W. Xu, S.K. Batabyal, S. Zhang, A. Cao, L.H. Wong, Nanotechnology 27, 20LT01 (2016)

150. J. Deng, L. Qiu, X. Lu, Z. Yang, G. Guan, Z. Zhang, H. Peng, J. Mater. Chem. A 3, 21070 (2015)

151. Y. Liu, S. Ji, S. Li, W. He, K. Wang, H. Hu, C. Ye, Study on holetransport-material-free planar $\mathrm{TiO}_{2} / \mathrm{CH} 3 \mathrm{NH} 3 \mathrm{PbI} 3$ heterojunction solar cells: the simplest configuration of a working perovskite solar cell. J. Mater. Chem. A 3, 14902-14909 (2015)

152. F.C. Hanusch, E. Wiesenmayer, E. Mankel, A. Binek, P. Angloher, C. Fraunhofer, N. Giesbrecht, J.M. Feckl, W. Jaegermann, D. Johrendt, T. Bein, P. Docampo, Efficient planar heterojunction perovskite solar cells based on formamidinium lead bromide. J. Phys. Chem. Lett. 5, 2791-2795 (2014) 